\title{
The Yellow Fluorescent Protein (YFP-H) Mouse Reveals Neuroprotection as a Novel Mechanism Underlying Chondroitinase ABC-Mediated Repair after Spinal Cord Injury
}

\author{
Lucy M. Carter, ${ }^{\star}$ Michelle L. Starkey, ${ }^{\star}$ Sonia F. Akrimi, Meirion Davies, Stephen B. McMahon, and \\ Elizabeth J. Bradbury \\ Neurorestoration Group, Wolfson Centre for Age-Related Diseases, King’s College London, London SE1 1UL, United Kingdom
}

\begin{abstract}
Chondroitinase $\mathrm{ABC}(\mathrm{ChABC})$ represents a promising therapeutic strategy for the treatment of spinal cord injury due to its potent effects on restoring function to spinal-injured adult mammals. However, there is limited mechanistic insight as to the underlying effects of $\mathrm{ChABC}$ treatment, where the effects are mediated, and which signaling pathways are involved in ChABC-mediated repair. Here we use a transgenic (YFP-H) mouse to demonstrate that cortical layer V projection neurons undergo severe atrophy 4 weeks after thoracic dorsal column injury and that $\mathrm{ChABC}$ is neuroprotective for these neurons after ICV infusion. ChABC also prevented cell atrophy after localized delivery to the spinal cord, suggesting a possible retrograde neuroprotective effect mediated at the injury site. Furthermore, neuroprotection of corticospinal cell somata coincided with increased axonal sprouting in the spinal cord. In addition, Western blot analysis of a number of kinases important in survival and growth signaling revealed a significant increase in phosphorylated ERK1 at the spinal injury site after in vivo ChABC treatment, indicating that activated ERK may play a role in downstream repair processes after ChABC treatment. Total forms of PKC and AKT were also elevated, indicating that modification of the glial scar by ChABC promotes long-lasting signaling changes at the lesion site. Thus, using the YFP-H mouse as a novel tool to study degenerative changes and repair after spinal cord injury we demonstrate, for the first time, that $\mathrm{ChABC}$ treatment regulates multiple signaling cascades at the injury site and exerts protective effects on axotomized corticospinal projection neurons.
\end{abstract}

Key words: spinal cord injury; proteoglycan; neuroprotection; regeneration; repair; transgenic

\section{Introduction}

A key factor preventing growth and regeneration in the adult mammalian CNS is the presence of chondroitin sulfate proteoglycans (CSPGs) (Busch and Silver, 2007; Galtrey and Fawcett, 2007). CSPGs are inhibitory extracellular matrix molecules present throughout development and in the adult and are important for guidance and stability (Faissner and Steindler, 1995). CSPGs become upregulated around CNS injury sites (Asher et al., 2000, 2002; Jones et al., 2003; Tang et al., 2003) and are potent inhibitors of neurite outgrowth for adult neurons (Snow et al., 1990; Dou and Levine, 1994; Smith-Thomas et al., 1994; Davies et al., 1999). Degradation of the glycosaminoglycan (GAG) compo-

\footnotetext{
Received May 15, 2008; revised Nov. 7, 2008; accepted Nov. 10, 2008.

This work was supported by the United Kingdom Medical Research Council and the International Spinal Research Trust. We thank Jodie Hall, Tom Hutson, and Sophie Pezet for expert assistance and Tim Boucher for critical review of this manuscript.

*L.M.C. and M.L.S. contributed equally to this work.

Correspondence should be addressed to Lucy M. Carter, Neurorestoration Group, Wolfson Centre for Age-Related Diseases, King's College London, Wolfson Wing, Hodgkin Building, Guy's Campus, London Bridge, London SE1 1UL, UK. E-mail: lucy.m.carter@kcl.ac.uk.

M. L. Starkey's present address: Brain Research Institute, Department of Neuromorphology, University of Zurich, Winterthurerstrasse 190, 8057 Zurich, Switzerland.

DOI:10.1523/JNEUROSCI.2217-08.2008

Copyright $\odot 2008$ Society for Neuroscience $\quad$ 0270-6474/08/2814107-14\$15.00/0
}

nent of CSPG molecules using chondroitinase ABC (ChABC) renders inhibitory substrates more permissive to growth (McKeon et al., 1995; Zuo et al., 1998; Grimpe et al., 2005) and, when delivered in vivo, enhances axon regeneration (Moon et al., 2001; Bradbury et al., 2002; Chau et al., 2004; Houle et al., 2006; Cafferty et al., 2007; Massey et al., 2008), plasticity, and sprouting (Pizzorusso et al., 2002; Barritt et al., 2006; Massey et al., 2006; Cafferty et al., 2008) after CNS injury. More importantly, beneficial effects on functional recovery after ChABC treatment have been demonstrated in spinal-injured adult rats in a number of experimental paradigms, including improvements in locomotor and proprioceptive function after dorsal column injury (Bradbury et al., 2002), locomotion and bladder function after compression injury (Caggiano et al., 2005), locomotion after complete transection (Fouad et al., 2005), and forelimb symmetry after hemisection (Yick et al., 2004). The effectiveness of ChABC treatment has also recently been demonstrated in larger mammals, with ChABC treatment promoting skilled locomotor recovery in spinal-injured adult cats (Tester and Howland, 2008).

Thus, ChABC treatment is emerging as one of the most promising therapeutic strategies for the treatment of spinal cord injury. However, mechanistic insight into underlying repair mechanisms remains limited (Bradbury and McMahon, 2006; Crespo et 
al., 2007). While the majority of studies have focused on studying regeneration and sprouting of injured axons, little is known about responses at the level of the cell soma of injured neurons after spinal cord injury, whether repair is mediated at the cell body or the injury site, and which intracellular signaling cascades may be regulated by ChABC treatment. Here we use a yellow fluorescent protein (YFP)-expressing mouse (YFP-H line) (Feng et al., 2000) to visualize the entire corticospinal tract (CST), from the cell bodies in layer $\mathrm{V}$ of the cortex through to their projecting axons in the spinal cord. Using this transgenic methodology as a novel tool to study degenerative changes after spinal cord injury we demonstrate that $\mathrm{ChABC}$ treatment prevents atrophy of corticospinal projection neurons after a thoracic dorsal column lesion. Neuroprotective effects may originate at the injury site since treatment of cell bodies and/or the spinal cord resulted in similar rescue effects, and also corresponded with increased sprouting of injured axons and regulation of multiple signaling cascades in the spinal cord. These findings demonstrate neuroprotection as a novel mechanism underlying the reparative effects of ChABC after spinal cord injury.

\section{Materials and Methods}

\section{YFP-H mice}

YFP-H mice [B6.Cg-TgN(Thy1-YFP-H)2Jrs, Jackson Laboratories], originally described by Feng et al. (2000), were received as a generous gift from Dr. Michael Coleman (The Babraham Institute, Cambridge, UK). The YFP-H line was maintained as transgenic heterozygotes by a transgenic $\times$ homozygous wild-type (C57 BL/6; Harlan) cross. YFP-positive mice were phenotyped as previously described (English et al., 2005). Briefly, ear notches were taken under minimal restraint at weaning on postnatal day 21 then the skin was pulled apart with fine forceps to expose the subcutaneous tissue, and mounted onto a microscope slide for examination under fluorescein isothiocyanate (FITC) illumination (Carl Zeiss, Axioplan 2). Animals were considered positive for the YFP transgene if fluorescent peripheral axons were observed.

\section{Animals and experimental groups}

Eighty-two adult male and female YFP-positive mice (12 weeks old, $20-25 \mathrm{~g}$ ) were used in these studies. For assessment of pyramidal layer $\mathrm{V}$ neuronal degeneration over time, animals received a spinal cord injury and were perfused at 2 weeks $(n=4)$ or 4 weeks $(n=4)$ after lesion; sham surgery animals served as uninjured controls $(n=4)$. To determine the appropriate region of the cortex for assessing degenerative changes after injury a further group of naive $(n=3)$ and spinal-injured $(n=3)$ animals received an injection of Fast Blue tracer and tissue was taken at either 1 week (injection only) or 4 weeks (injection + lesion) after surgery. For determining neuroprotective effects after treatment, animals received a spinal cord injury and were treated with a control enzyme (penicillinase, ICV delivery, $n=12$ ) or ChABC (ICV delivery, $n=12$; IT delivery, $n=12$ ). Tissue was processed at 4 weeks after lesion for analysis of neuroprotection ( $n=4$ per group) and Western blotting ( $n=4$ per group) and immunohistochemical analysis ( $n=4$ per group) with $n=4$ uninjured controls included in each condition. In a further group of spinal-injured animals, apoptosis was assessed using a TUNEL assay at 1 week $(n=4)$ and 4 weeks $(n=4)$ after injury, with $n=4$ sham-operated controls in each case.

\section{Spinal cord injury and cannulation surgery}

All surgical procedures were performed in accordance with U.K. Home Office regulations (European Communities Council Directive of 24 November 1986 (86/609/EEC)) and sterile precautions were used throughout. Mice were anesthetized with Avertin mouse anesthetic (1.25 g of 2,2,2-tribromoethanol/100 ml of tert-amyl alcohol; both Sigma; diluted to $20 \mathrm{mg} / \mathrm{ml}$ with saline) administered i.p. $(0.5 \mathrm{ml} / 20 \mathrm{~g})$, with readministration as a half dose as required. For ICV cannulation, anesthetized mice were placed into a stereotaxic frame, the skull was exposed, and a hole made with a 25 gauge needle (with coordinates $-0.5 \mathrm{~mm}$ from bregma, $1 \mathrm{~mm}$ lateral to the midline). A steel cannula composed of an insertion end made of a 26 gauge needle with a $90^{\circ}$ bend at $2.5 \mathrm{~mm}$ and an exposed end, connected to $30-\mathrm{mm}$-long flexible SILASTIC tubing (VWR) was inserted into the hole and secured into place using cyanoacrylate gel (RS Components). The skin over the skull was sutured with 6-0 Vicryl sutures (Ethicon, Johnson \& Johnson) leaving only the tubing exposed. For IT cannulation, a partial laminectomy was performed at the T10 spinal level. After application of lignocaine, the dura was incised and $20 \mathrm{~mm}$ Micro-Renathane tubing (inner diameter $0.12 \mathrm{~mm}$, outer diameter $0.25 \mathrm{~mm}$; Braintree Scientific) attached to $40 \mathrm{~mm}$ SILASTIC tubing was inserted $5 \mathrm{~mm}$ intrathecally to lie just rostral to the T12 spinal segment and anchored to the rostral vertebral bone with cyanoacrylate gel. The other end was guided under the skin and externalized and secured as above. Animals were placed on a heated blanket during recovery, before being returned to their home cage. One day after cannulation surgery mice were re-anesthetized with Avertin, as above, and received a dorsal column crush injury. Surgery was adapted from methods described previously for rats (Bradbury et al., 1999, 2002). Briefly, mice were prepared for surgery by shaving and disinfecting the dorsal surface of the back. After incision, muscle tissue was cleared from the dorsal processes of the lower thoracic vertebrae and a laminectomy was performed to expose the dorsal surface of the T12 spinal cord. A piece of Gelfoam soaked with lignocaine $(0.2 \%)$ was placed on the spinal cord for $2 \mathrm{~min}$, then the dura was opened. Lignocaine was reapplied, as above, and then the exposed dorsal columns were crushed to a depth of $0.5 \mathrm{~mm}$ into the cord using a pair of fine forceps (Fine Science Tools), which were held in place for $10 \mathrm{~s}$ before being removed. The muscle and skin layers were sutured with 6-0 Vicryl sutures. Mice were placed on a heated blanket during recovery, before being returned to their home cage. Control mice received sham surgery, which was identical to the above up to the laminectomy after which the muscle and skin layers were sutured with 6-0 Vicryl sutures without lesion.

\section{ICV delivery of $C h A B C$}

Immediately after the dorsal column lesion, mice received either $6 \mu \mathrm{l}$ ( 10 $\mathrm{U} / \mathrm{ml}$ ) high-purity, protease-free ChABC (Seikagaku) or penicillinase (Sigma, same $\mu \mathrm{g}$ protein delivered) followed by a $3 \mu \mathrm{l}$ saline flush. Treatment was delivered as a slow bolus IT or ICV injection using a Hamilton syringe inserted into the externalized cannula tubing, with tubing sealed after injection with cyanoacrylate gel. Mice received further bolus injections on days $2,4,6,8$, and 10 after dorsal column lesion, with injections performed under isoflurane anesthesia (Abbott Laboratories; $5 \%$ induction and $2 \%$ maintenance).

\section{Fast Blue retrograde tracing}

To determine the appropriate cortical level and regions of interest for analyzing degenerative changes in corticospinal neurons after thoracic spinal cord injury retrograde tracing was undertaken using Fast Blue. Briefly, the T12 spinal cord was exposed as above and a drawn glass micropipette (external tip diameter $<15 \mu \mathrm{m}$ ) was advanced through the dorsal columns using a Narishige hydraulic manipulator. Fast Blue $(0.5$ $\mu l, 2 \%$; Sigma) was injected at depths of $0.4 \mathrm{~mm}$ and $0.3 \mathrm{~mm}$ from the surface of the spinal cord. The micropipette was left in situ for $20 \mathrm{~s}$ before being withdrawn. In a second group of mice, a dorsal column crush lesion was then performed at the site of injection, as above.

\section{Tissue processing}

For analysis of cortical layer V neurons, mice were deeply anesthetized with pentobarbitone $(80 \mathrm{mg} / \mathrm{kg}$, i.p.) and transcardially perfused with 10 $\mathrm{ml}$ of heparinized saline followed by $50 \mathrm{ml}$ of paraformaldehyde ( $4 \%$ in $0.1 \mathrm{M}$ phosphate buffer). Brains and spinal cords were dissected, postfixed in $4 \%$ paraformaldehyde $\left(2 \mathrm{~h}\right.$ at $4^{\circ} \mathrm{C}$ ), and transferred to PBS (plus $0.1 \%$ sodium azide) then embedded in gelatin ( $10 \%, 300$ bloom, Sigma). Gelatin blocks were hardened in $4 \%$ paraformaldehyde, and then $30 \mu \mathrm{m}$ free-floating serial coronal sections were cut on a vibratome (Leica) and collected in 24 -well plates containing PBS (plus $0.1 \%$ sodium azide). For immunohistochemical analysis, animals were perfused as above (with the addition of $15 \%$ picric acid) and postfixed tissue was transferred to $20 \%$ sucrose (in $0.1 \mathrm{M} \mathrm{PB}$, overnight at $4^{\circ} \mathrm{C}$ ) then blocked in OCT embedding compound (BDH) for cryostat sectioning. Sagittal spinal cord sections $(20 \mu \mathrm{m})$ were thaw mounted onto Superfrost Plus slides and 
coronal brain sections ( $30 \mu \mathrm{m}$ ) were collected and stored free-floating as above. For Western blot analysis, after a rapid transcardial saline flush, tissue pieces from the spinal cord were fresh dissected and snap frozen in liquid nitrogen. To minimize sampling inconsistencies the injury site was routinely identified by the site of laminectomy and injury adhesions on the cord surface. A $4 \mathrm{~mm}$ tissue piece spanning the lesion site (with the lesion centered) was dissected.

\section{Analysis of cell size}

All photomicrographs were acquired under FITC, DAPI, and TRITC illumination, using a Carl Zeiss AxioImager Z1 microscope and Zeiss $\mathrm{MRm}$ AxioCam. High-magnification images were acquired as $Z$-stacks (1.5 $\mu \mathrm{m} Z$ interval) using an ApoTome imaging system fitted to the AxioImager $Z 1$ microscope.

Analysis of YFP-labeled neurons after injury and treatment. Cortical regions for analysis of CSN cell size were selected according to the distribution of Fast Blue-labeled CSNs retrogradely traced from the site of a T12 dorsal column injury. Dual labeling of Fast Blue tracing and YFPpositive cortical neurons were viewed in the coronal plane using AxioVision LE V4.6.1 (Carl Zeiss) in serial sections from $+0.14 \mathrm{~mm}$ through $-0.46 \mathrm{~mm}$, corresponding to bregma. The area containing Fast Bluelabeled cells spanned an $800 \mu \mathrm{m}$ region of cortical layer $\mathrm{V}$, located 400 $\mu \mathrm{m}$ lateral to the midline interhemispheric fissure. Therefore, for analysis of cell size after spinal cord injury, one section per animal corresponding to bregma $+0.14 \mathrm{~mm}$, bregma $-0.10 \mathrm{~mm}$, and bregma $-0.46 \mathrm{~mm}$ (Paxinos and Franklin, 2001) was selected and a box $(800 \times 400 \mu \mathrm{m})$ was positioned over cortical layer $\mathrm{V}, 400 \mu \mathrm{m}$ from the interhemispheric fissure. The profiles of all YFP-positive layer V neurons within this area (which contained $\sim 100$ cells per section) were then outlined using AxioVision analysis package, by an investigator blinded to the treatment groups. The bound diameter of each profile was recorded and a circular area was then derived for each profile. Size/frequency distributions were tabulated for each animal and a mean distribution calculated for each treatment group.

Comparison of YFP and retrograde labeling. To directly compare measurements of CSN cell size using intrinsic YFP-labeling in the YFP-H mouse with more traditional tracing methods, cell size distributions were determined separately for YFP-labeled neurons and Fast Blue-labeled neurons in animals which had undergone either a single intraspinal injection of Fast Blue or injection of Fast Blue plus dorsal column crush lesion. Photomicrographs were opened in AxioVision analysis software and the profiles of all YFP-positive layer V neurons and all Fast Bluelabeled neurons, sampled as above, were outlined separately in duallabeled images. Size/frequency distributions were then determined separately for both markers allowing a direct comparison of the two labels.

\section{Analysis of cell survival}

The total YFP-positive cell count within the sampling area was recorded from one tissue section per animal and a mean cell count determined for each group. For assessment of TUNEL reactivity in layer V after spinal cord injury, triple-labeled (YFP/TUNEL/DAPI) high-power ApoTome $Z$-stack images were acquired through the region of interest. In the resultant images, colocalization of TUNEL staining with a DAPI-labeled nuclear profile was defined as an apoptotic cell and all TUNEL-reactive cells residing in layer $\mathrm{V}$ were counted in three sections per animal. Layer $\mathrm{V}$ was defined with reference to the distribution of DAPI-reactive nuclei and YFP-labeled pyramidal neurons.

\section{Analysis of fiber growth at the spinal cord injury site}

The growth of intrinsically labeled YFP fibers was assessed within the lesion epicenter. The borders of the lesion were defined by the abrupt halting of YFP-labeled descending CST and ascending dorsal column axons, with the lesion epicenter apparently devoid of YFP-labeling (see Fig. $7 B$ ). This allowed an unimpeded view of fine YFP-labeled fibers growing within the lesion epicenter. The total number of YFP-labeled fibers within this zone was quantified in three sagittal sections through the dorsal funiculus per animal by an investigator blind to the treatment group. Mean fiber counts were then calculated for each treatment group.

\section{Immunohistochemistry and TUNEL staining}

TUNEL staining. TUNEL was performed using an indirect ApopTag Red in situ apoptosis detection kit (Millipore) according to the manufacturer's instructions. Briefly, sections were permeabilized in PBS plus $0.5 \%$ Triton X-100 (10 $\mathrm{min})$, treated with equilibration buffer (5 min, room temperature) and then incubated in a humidified atmosphere with terminal deoxynucleotidyl transferase (TdT), in a reaction buffer containing digoxigenin-dUTP $\left(1 \mathrm{~h}, 37^{\circ} \mathrm{C}\right)$. Sections were then incubated under agitation in stop/wash buffer ( $10 \mathrm{~min}$ ) and washed in 3 changes of PBS before incubation in rhodamine-conjugated anti-digoxigenin antibody (30 min, room temperature). Negative control tissue was treated as above with the omission of active TdT enzyme. As a positive control, cortical tissue was prepared by pretreatment with DNaseI. Sections were treated with DN buffer ( $30 \mathrm{~mm}$ Tris, pH 7, $4 \mathrm{~mm} \mathrm{MgCl}_{2}, 0.1 \mathrm{~mm}$ DTT; 5 min) before incubation with DNaseI solution $(1000 \mathrm{U} / \mathrm{ml}$ in DN buffer; 10 $\mathrm{min}$, room temperature). Predigested sections were washed in 6 changes of double distilled water before TUNEL processing as described above. TUNEL-reacted sections were coverslipped in Vectashield mounting medium containing $0.5 \mu \mathrm{g} / \mathrm{ml}$ DAPI as a nuclear counterstain. (Vector Laboratories).

Chondroitin-4-sulfate. To assess the CSPG-GAG digestion, brain and spinal cord sections were processed for chondroitin-4-sulfate (C-4-S) immunostaining to reveal digested sugar stub regions as previously described (Barritt et al., 2006). Briefly, sections were incubated in the following (with three PBS washes between each step): hydrogen peroxide $(0.3 \%, 30 \mathrm{~min})$, mouse anti-C-4-S (1:5000, overnight; ICN Biochemicals), biotinylated horse anti-mouse secondary antibody (1:400, $90 \mathrm{~min}$; Jackson ImmunoResearch), ABC reagent (1:250, 20 min; Vector Laboratories), biotinyl tyramide (1:75, $10 \mathrm{~min}$; PerkinElmer Life Sciences), and ExtrAvidin TRITC (1:200, 2 h; Sigma). Free-floating brain sections were slide mounted and all slides were coverslipped with Vectashield mounting medium.

Wisteria floribunda agglutinin. To evaluate degradation of CSPGs within cortical peri-neuronal nets (PNNs), free-floating brain sections were processed for WFA histochemistry by incubation in the following: biotin-conjugated Wisteria floribunda agglutinin (WFA, $10 \mu \mathrm{g} / \mathrm{ml}$, overnight; Sigma) and then ExtrAvidin TRITC (1:200, 2 h, Sigma). Sections were mounted and coverslipped as above. For quantification of cortical PNN labeling, the region of interest was defined relative to the interhemispheric fissure (as above) and the total number of WFA-reactive profiles was quantified across all cortical layers in 2 sections per animal by an investigator blind to the treatment group. Mean counts were then derived for each treatment group.

\section{Western blotting}

Samples were homogenized in ice-cold lysis buffer (20 mm Tris, pH 8, $137 \mathrm{~mm} \mathrm{NaCl}, 10 \%$ glycerol, 1\% Nonidet P-40, 2 mм EDTA, 1 mм PMSF, antipain, anti-leupeptin, pepstatin (all $10 \mu \mathrm{g} / \mathrm{ml}$ ), $1 \mathrm{~mm}$ sodium vanadate, $5 \mathrm{~mm} \mathrm{NaF}$ ). Lysates were left under agitation for $2 \mathrm{~h}$ on ice before centrifugation (1200 rpm, $20 \mathrm{~min}, 4^{\circ} \mathrm{C}$ ) and collection of the supernatant. The protein concentration of lysates was estimated using a colorimetric protein assay according to the manufacturer's instructions (BCA protein assay, Pierce). Fifteen micrograms of total protein from each sample were electrophoresed in loading buffer ( $60 \mathrm{~mm}$ TrisCl, $\mathrm{pH} 6.8,2 \%$ SDS, $2 \% \beta$-mercaptoethanol, $10 \%$ glycerol, $0.01 \%$ bromophenol blue) across a $10 \%$ acrylamide gel $(2 \mathrm{~h}$ at $120 \mathrm{mV})$. Proteins were transferred to a nitrocellulose membrane using a semidry transfer method (45 min, 15 $\mathrm{mV})$. Membranes were then blocked in skimmed milk $(10 \%, 1 \mathrm{~h})$ before incubation with a phospho-specific primary antibody: rabbit anti-phospho ${ }^{\text {(thr202/tyr204) }}$ p44/42 MAPK, rabbit anti-phospho ${ }^{(\beta I I}$ ser660) $\mathrm{PKC}$ (pan), rabbit anti-phospho ${ }^{\text {(ser473) }}{ }^{\text {AKT, rabbit anti-phospho }}{ }^{(\text {ser9) }}$ GSK3 $\beta$ (all 1:1000, overnight; Cell Signaling), and mouse anti- $\beta$-III tubulin (1: 1000 , overnight; Promega). Membranes were washed and then incubated with secondary antibodies (donkey anti-rabbit IRDye 800, goat antimouse IRDye 680, 1 h; LiCor Biosciences) and visualized using Odyssey Infrared imaging system (LiCor Biosciences). Membranes were stripped for $45 \mathrm{~min}$ at $50^{\circ} \mathrm{C}$ in stripping buffer (2\% SDS, $0.8 \%$ $\beta$-mercaptoethanol, $12.5 \%$ TrisCl, $\mathrm{pH} 6.8$ ), blocked again in skimmed milk, and reprobed for the corresponding nonphosphorylated form of 
each kinase: rabbit anti-AKT, rabbit antip44/42 MAPK, rabbit anti-GSK3 $\beta$ (all 1:1000, overnight; Cell Signaling), or rabbit anti-PKC $\beta$ II (1:500, Santa Cruz Biotechnology). Integrated band intensities for phosphorylated and total forms of each kinase and $\beta$-III-tubulin were quantified for each sample using Odyssey software. Densitometric values for target proteins or phosphoproteins were normalized against the $\beta$-III-tubulin loading control for each sample and mean expression data were calculated from 4 animals per treatment group.

\section{Statistical analysis}

For analysis of corticospinal somata size, size/ frequency distributions were plotted as histograms representing mean frequency \pm SEM for each treatment ( $n=4$ per group). Using SPSS 16.0, pairwise statistical comparisons of cell size distributions were made between sham, lesion plus penicillinase, lesion plus ICV ChABC and lesion plus IT ChABC using a two-sample Kolmogorov-Smirnov test. Tests were performed against a significance threshold of 0.01 to correct for multiple testing. Quantification of YFPpositive fiber growth and WFA-labeled PNN staining was compared between lesion plus penicillinase, lesion plus ICV ChABC, and lesion plus IT ChABC groups ( $n=4$ per group) using a one-way ANOVA with Tukey post hoc analysis. Densitometric quantifications of Western blots, normalized against loading control, were compared between treatment groups ( $n=4$ per group) using one-way ANOVA with block design and Tukey post hoc analysis.

\section{Results}

\section{Expression of YFP in the naive} YFP-H mouse

Since YFP labels neurons in their entirety (including cell bodies, axons, nerve terminals, dendrites, and dendritic spines) (Feng et al., 2000), the CST projection was examined in serial sections throughout the neuraxis of naive YFP-H mice. In sagittal sections through the brain, intense YFP expression was observed in layer $\mathrm{V}$ pyramidal neurons in the cortex (Fig. $1 A, B$ ), where the cell bodies of corticospinal neurons (CSNs) reside, and in projecting fiber bundles within the internal capsule (Fig. $1 A)$ and the pyramids of the brainstem (Fig. $1 B$ ). Other regions of the brain expressing YFP included neurons in the CA1 field of the hippocampus and the granule cell layer of the dentate gyrus and some midbrain and brainstem nuclei (Fig. $1 A, B$ ). Intensely labeled CST projections could be clearly visualized in transverse sections through the brainstem, in the pyramidal tracts (Fig. $1 C$ ) and at the level of pyramidal decussation, where the majority of CST axons decussate to project dorsally (Fig. $1 D$ ). In the spinal cord, the major CST component in the ventral portion of the dorsal funiculus was intensely labeled at all spinal levels examined (Fig. $1 E, F)$. Other spinal cord systems also expressed YFP, including some ascending dorsal column axons, projections in the lateral and ventral columns, and motoneurons (Fig. $1 E, F)$. Thus, in the
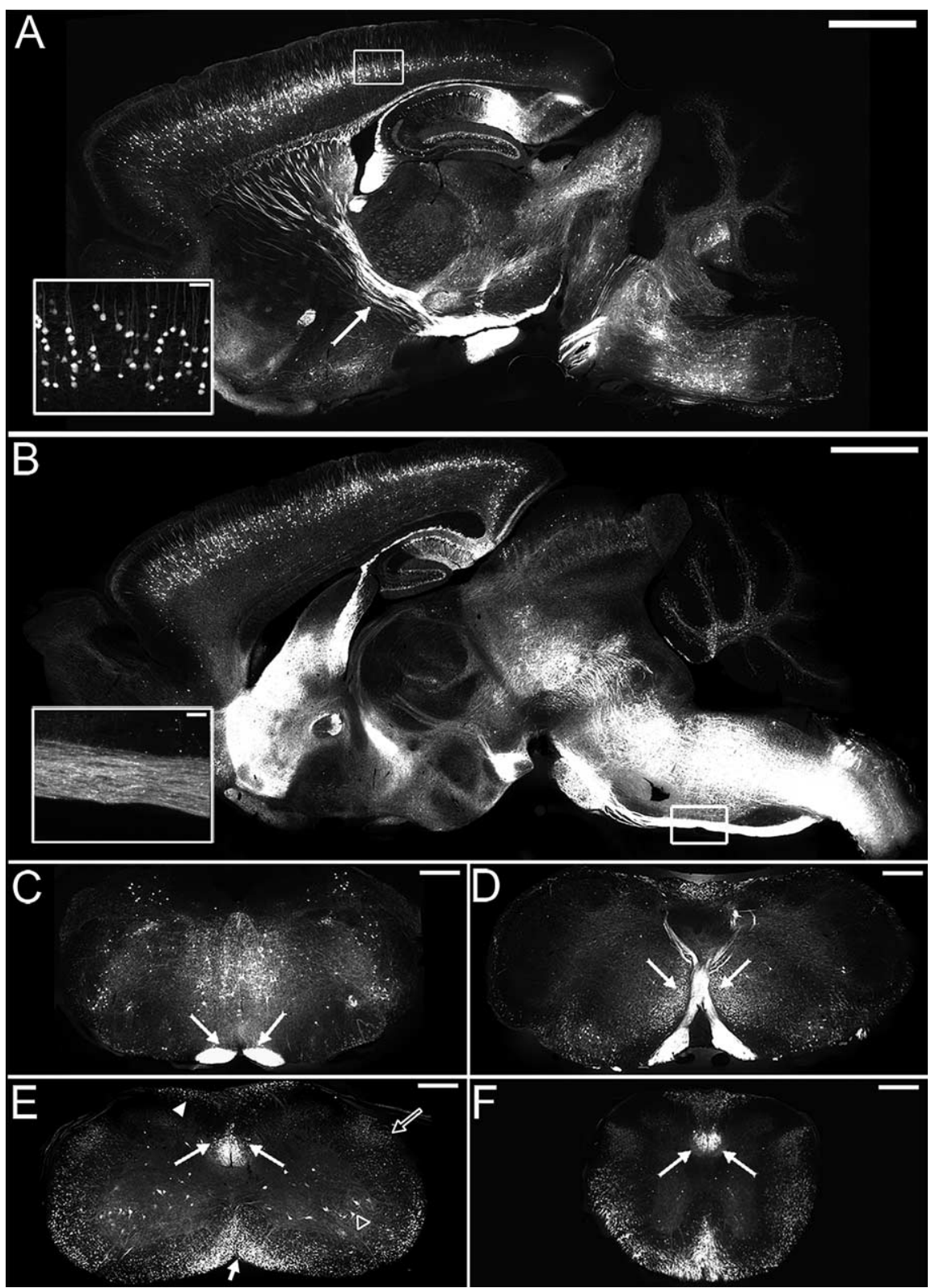

Figure 1. YFP labels corticospinal neurons in their entirety in the YFP-H mouse. Sagittal sections through the brain $(\boldsymbol{A}, \boldsymbol{B})$ identifying YFP expression in the naive YFP-H mouse. $\boldsymbol{A}$, Intense labeling is observed in the cell bodies and apical dendrites of layer $\checkmark$ pyramidal neurons (inset shows boxed area at high power) and their projecting axons within the internal capsule (arrow). $\boldsymbol{B}$, More medially, an intensely labeled bundle of corticospinal tract axons is observed in the pyramidal tract (inset shows boxed area at high power). In transverse sections through brainstem and spinal cord, intense YFP expression in corticospinal tract axons (arrows) is observed bilaterally in the brainstem pyramids $(\boldsymbol{C})$, the pyramidal tract decussation $(\boldsymbol{D})$, and the ventral portion of the dorsal columns in cervical $(\boldsymbol{E})$ and thoracic $(\boldsymbol{F})$ spinal cord. Other spinal systems also contain the YFP label, including spinal motoneurons (open arrowhead) and projections in the dorsal (arrowhead), ventral (short arrow), and lateral (open arrow) columns $(\boldsymbol{E})$. Scale bars: $500 \mu \mathrm{m}(\boldsymbol{A}, \boldsymbol{B}), 200 \mu \mathrm{m}(\boldsymbol{C}-\boldsymbol{F}), 50 \mu \mathrm{m}$ (insets).

YFP-H mouse CSNs are labeled in their entirety, with both cell bodies and their spinally projecting axons easily identifiable. This provides a unique opportunity for studying changes in this important descending projection after spinal cord injury.

Thoracic spinal cord injury leads to progressive atrophy, but not death, of corticospinal neurons in the YFP-H mouse

To determine whether degenerative changes could be observed in YFP-labeled pyramidal neurons in layer $\mathrm{V}$ of the cortex after a thoracic dorsal column lesion, cell atrophy and death were examined at several postinjury time points. Layer $\mathrm{V}$ pyramidal neurons 

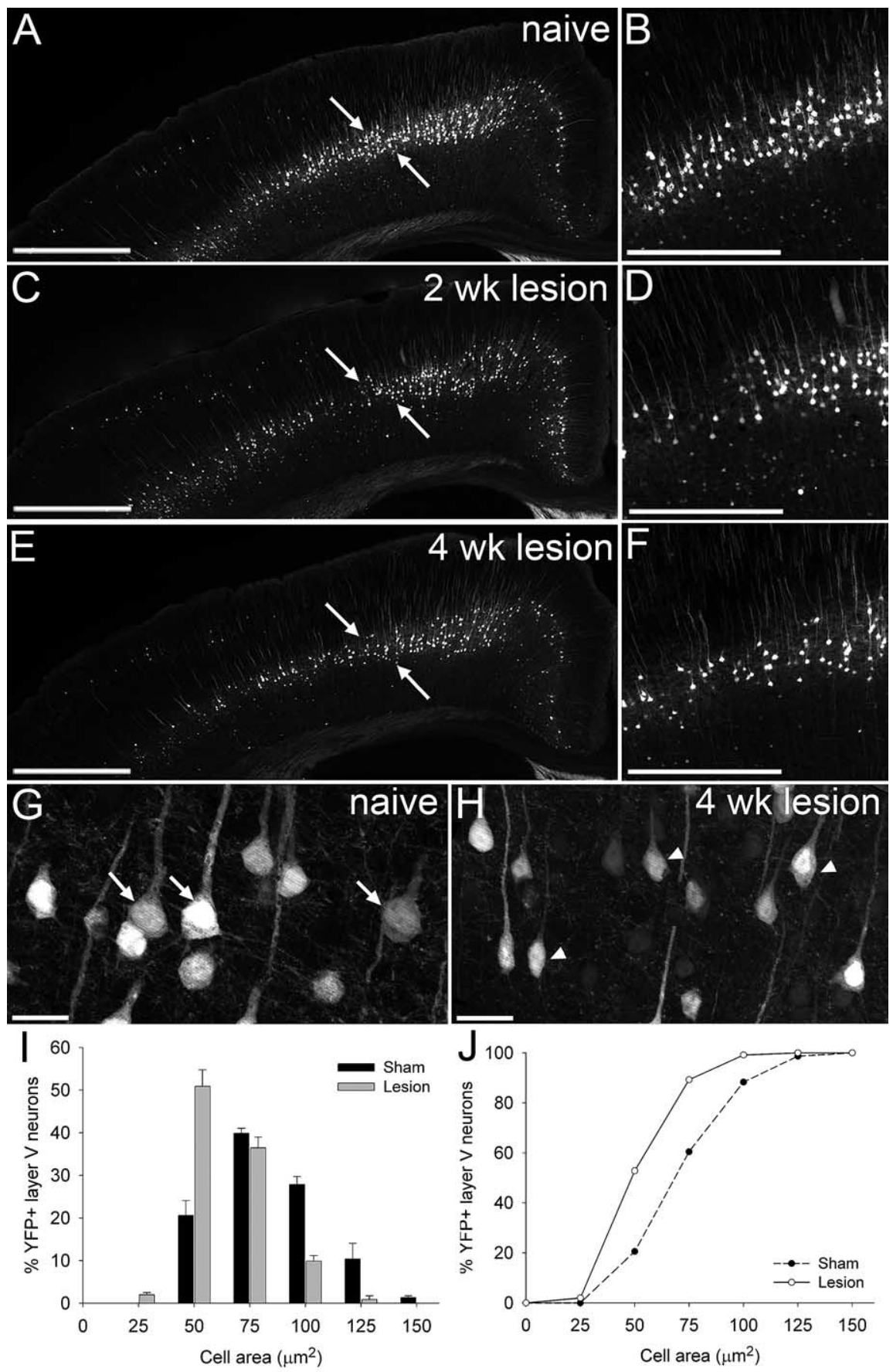

Figure 2. Spinal cord injury induces progressive atrophy of corticospinal neurons in the YFP-H mouse. Representative low ( $\boldsymbol{A}$, $\boldsymbol{C}, \boldsymbol{E})$ - and high $(\boldsymbol{B}, \boldsymbol{D}, \boldsymbol{F})$-power images of coronal sections through the YFP-H mouse sensorimotor cortex at bregma $-0.46 \mathrm{~mm}$ show injury-induced changes in YFP-labeled layer V pyramidal neurons. In naive (uninjured) animals $(\boldsymbol{A}, \boldsymbol{B})$, many large healthy pyramidal somata are apparent; arrows denote region of interest. After thoracic dorsal column lesion, progressive atrophy of these cells is observed at $2(\boldsymbol{C}, \boldsymbol{D})$ and $4(\boldsymbol{E}, \boldsymbol{F})$ weeks after injury. Higher-magnification images $(\boldsymbol{G}, \boldsymbol{H})$ highlight the striking contrast between large healthy somata in naive YFP-H mouse cortex ( $G$, arrows) and severely atrophied somata at 4 weeks after spinal cord injury $(\boldsymbol{H}$, arrowheads). Cell size distribution histogram $(\boldsymbol{I})$ and cumulative frequency $(\boldsymbol{J})$ plots demonstrate that YFP-labeled pyramidal neurons have undergone significant shrinkage at 4 weeks after lesion, with a significant leftward shift in cell size distribution toward smaller cell areas, compared with sham controls (two-sample Kolmogorov-Smirnov test, $p<0.001$ ). Scale bars: $500 \mu \mathrm{m}(\boldsymbol{A}, \boldsymbol{C}, \boldsymbol{E}), 250 \mu \mathrm{m}(\boldsymbol{B}, \boldsymbol{D}, \boldsymbol{F}), 25 \mu \mathrm{m}(\boldsymbol{G}, \boldsymbol{H})$.

showed progressive pathology after a T12 dorsal column lesion, with evidence of cell atrophy apparent at 2 weeks after injury, with the somata of many neurons appearing shrunken (Fig. $2 C, D)$, compared with the large healthy pyramidal neurons evi- dent in sham (uninjured) mice (Fig. $2 A, B, G)$. By 4 weeks after injury cell atrophy was severe, with a marked shrunken appearance of cell soma (Fig. 2E,F,H). Quantification revealed significant cell shrinkage in lesioned animals compared with sham controls at 4 weeks after injury (Fig. 2I), with a marked shift to the left in cumulative frequency distribution (indicating smaller cell sizes) confirming significant atrophy of layer $\mathrm{V}$ pyramidal neurons after thoracic dorsal column injury $(p<0.001$, Kolmogorov-Smirnov test $)$ (Fig. 2J).

A direct comparison of cell atrophy measurements obtained with intrinsic YFP-labeling compared with a more conventional retrograde tracing method showed the two techniques to give highly comparable measurements of cell soma size and distribution (Fig. 3). In both spinal-injured and uninjured YFP-H mice, YFP-labeling of cell soma closely matched Fast Blue cell soma labeling after injection of the tracer into the thoracic spinal cord (Fig. $3 A, B$ ). Cell size distributions (Fig. $3 C$ ) and cumulative frequency plots (Fig. 3D) determined from duallabeled sections showed no significant difference between YFP-labeling and retrograde tracing in either uninjured (tracer injection only) or spinal cord injured (lesion + tracer $)$ YFP-H mice $(p>0.05$, Kolmogorov-Smirnov test), with both techniques demonstrating a similar degree of CSN atrophy 4 weeks after thoracic spinal cord injury. Thus, intrinsic labeling of layer $\mathrm{V}$ projection neurons in the YFP-H mouse provides a reliable marker for measuring CSN cell size and atrophy after spinal cord injury.

As well as marked atrophy of surviving cells, there also appeared to be fewer cells in the region of interest after injury, compared with sham controls (Fig. 2A-F). However, the impression of empty space is partly due to the reduced YFP signal in the atrophied cell soma and proximal processes, rather than actual cell loss. Cell counts confirmed that although YFPlabeled CSNs underwent atrophy after thoracic dorsal column lesion, there was no significant cell loss, with mean cell numbers (within the region of interest) of $139 \pm 22$, compared with $128 \pm 14$ in sham controls and 4 week injured mice, respectively ( $p=0.6$, two-sided $t$ test). Furthermore, assessment of apoptotic cell death by TUNEL assay (Fig. 4) did not reveal any apoptotic nuclei in cortical layer $\mathrm{V}$, at either 1 week (data not shown) or 4 weeks (Fig. 4D) after dorsal column crush injury, suggesting that atrophy was not associated with ongoing apoptotic cell death of lesioned CSNs at these time points. 
ChABC promotes neuroprotection of corticospinal projection neurons after spinal cord injury in the YFP-H mouse To determine whether degenerative changes in YFP-labeled pyramidal neurons could be reversed after degradation of CSPGs, cell atrophy was examined at 4 weeks after injury in mice subjected to a thoracic dorsal column lesion and treated with penicillinase (a control enzyme treatment) or ChABC, delivered via intracerebroventricular (ICV) infusion. Atrophy was examined in two cortical regions that contained CSNs projecting to the thoracic spinal cord (determined by dual fluorescence of Fast Blue tracing and YFP-H labeling) (supplemental Fig. 1, available at www.jneurosci.org as supplemental material) and a third region, bregma +0.14 $\mathrm{mm}$, which acted as a control region to check for effects in neighboring uninjured projection neurons (supplemental Fig. 2, available at www.jneurosci.org as supplemental material). At bregma $-0.10 \mathrm{~mm}$ and $-0.46 \mathrm{~mm}$, cell atrophy was marked at 4 weeks after injury in animals treated with penicillinase (Fig. 5A, B, F and supplemental Fig. 3, available at www.jneurosci.org as supplemental material, respectively). In contrast, after ICV ChABC treatment, many more neurons with large normallooking somata were apparent in both regions (Fig. 5C, D, $G$ and supplemental Fig. 3 , available at www.jneurosci.org as supplemental material). A cell size distribution analysis revealed significant cell shrinkage after injury and penicillinase treatment compared with uninjured sham controls (Fig. $5 \mathrm{H}$ ), with a significant leftward shift in cumulative frequency distribution confirming significant cell atrophy (Fig. 5I) $(p<0.001$, lesion plus penicillinase compared with sham controls, Kolmogorov-Smirnov). ICV delivery of ChABC after thoracic dorsal column injury led to a reversal of cell atrophy, with fewer cells of small diameter and more cells of large diameter (Fig. 5G,H). This reversal of atrophy was almost complete at bregma $-0.10 \mathrm{~mm}$, with the cumulative frequency curve almost identical to that of the uninjured sham group (Fig. 5I) (lesion plus ICV ChABC significantly different from lesion plus ICV penicillinase, $p<0.001$, and not significantly different from sham, $p=0.76$, Kolmogorov-Smirnov). At bregma $-0.46 \mathrm{~mm}$ rescue from atrophy was partial, with the distribution curve after ChABC treatment lying mid-way between the lesion plus penicillinase group and sham controls (supplemental Fig. 3, available at www.jneurosci.org as supplemental material) (lesion plus ICV ChABC significantly different from lesion plus penicillinase, $p<0.001$, and significantly different from sham, $p<0.001$, Kolmogorov-Smirnov). Thus, ICV delivery of $\mathrm{ChABC}$ can prevent the atrophy that occurs in the cell bodies of corticospinal neurons after injury to their axonal projections in the spinal cord.

\section{Intrathecal and intracerebroventricular delivery of $\mathrm{ChABC}$ promote equivalent protection of lesioned CSNs}

Since ICV delivery of ChABC can degrade CSPGs throughout the neuraxis (García-Alías et al., 2008), it is not certain whether neu- roprotective effects after ICV delivery of ChABC are mediated via changes at the level of the cell body in the cortex or at the site of the injured axons in the spinal cord. Therefore, the effects of ChABC treatment after intrathecal (IT) administration, which largely restricts delivery of $\mathrm{ChABC}$ to the spinal cord, were also determined. Strikingly, the neuroprotective effects after IT treatment were virtually identical to those observed after ICV treatment, with the cell size distribution revealing fewer small diameter cells and many more cells of larger diameter (Fig. $5 \mathrm{H}$ ) and the cumulative frequency distribution curve perfectly aligned with the ICV ChABC treatment group and the uninjured sham controls, indicating a complete rescue from atrophy at bregma $-0.10 \mathrm{~mm}$ (Fig. 5I) (lesion plus IT ChABC significantly different from lesion plus penicillinase, $p<0.001$, and not significantly different from lesion plus ICV ChABC or sham, $p=0.9$, Kolmogorov-Smirnov) and partial rescue at bregma $-0.46 \mathrm{~mm}$ (supplemental Fig. 3, available at www.jneurosci.org as supplemental material) (lesion plus IT ChABC significantly different from lesion plus penicillinase, $p<0.001$, and significantly different from sham, $p<0.001$, Kolmogorov-Smirnov test). Comparison of mean cell area across both sites again demonstrated significant atrophy of CSNs 4 weeks after spinal cord injury and penicillinase treatment (mean cell area \pm SEM; sham $63.1 \pm 0.6 \mu \mathrm{m}^{2}$; lesion plus penicillinase $54.3 \pm 0.6 \mu \mathrm{m}^{2}, p<0.001$, one-way ANOVA, Tukey post hoc test). This atrophy was reduced by $>50 \%$ after ChABC treatment, with equivalent neuroprotection after either ICV or IT delivery of ChABC (mean cell area \pm SEM; lesion plus ICV ChABC 58.7 $\pm 0.7 \mu \mathrm{m}^{2}$ and lesion plus IT ChABC $59.3 \pm$ $0.5, p<0.01$, one-way ANOVA, Tukey post hoc test). Thus, the 

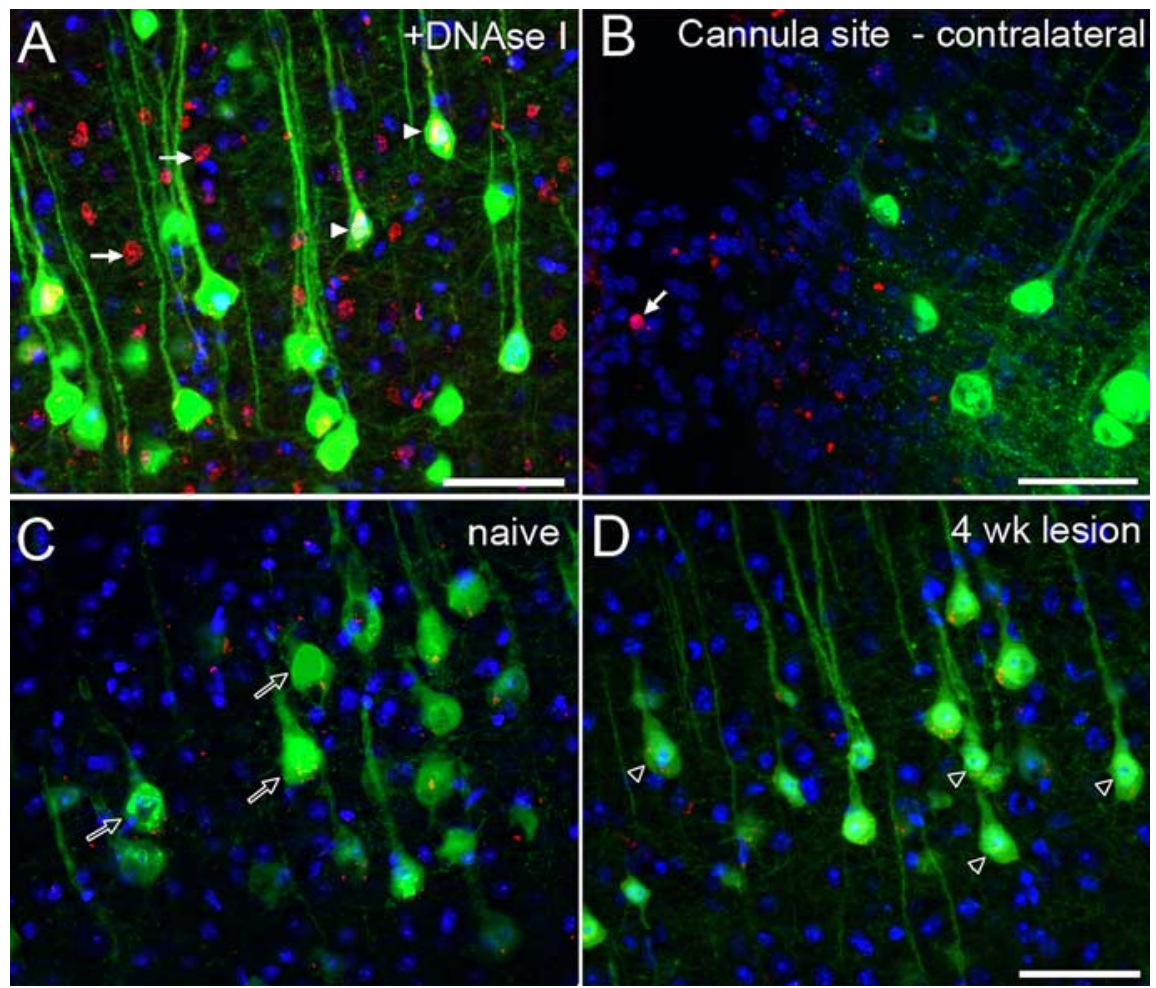

Figure 4. Lack of TUNEL-reactive apoptosis in layer V projection neurons after thoracic spinal cord injury in the YFP-H mouse. TUNEL-labeled coronal sections of layer V cortex in the YFP-H mouse. In control samples, pretreatment of sections with DNasel (a positive control) results in extensive TUNEL signal (red) throughout the tissue $(\boldsymbol{A})$. Many TUNEL-reactive nuclei (arrows) are observed within layer $V$, and TUNEL reactivity can also be detected within the nuclei of YFP-labeled CSNs (arrowheads). At the site of ICV cannulation in the contralateral hemisphere (B), TUNEL-reactive apoptotic nuclei (arrow) are sporadically detected (without pretreatment of the tissue) in the area of reactive tissue, bordering the cannula site. At bregma $-0.46 \mathrm{~mm}$ in naive animals (C), only background labeling is apparent, and no TUNEL-reactive nuclei are detected within layer V pyramidal neurons (open arrows). Four weeks after dorsal column crush injury (D), no TUNEL-reactive nuclei are detected in either YFP-positive CSNs or unlabeled cells, though many YFP-labeled somata appear shrunken in size (open arrowheads). Scale bars, $50 \mu \mathrm{m}$.

effects of ChABC on promoting neuroprotection of lesioned CSNs may be mediated at the injury site in the spinal cord, rather than at the cell body. To explore this further, we examined the pattern of CSPG degradation in cortex and spinal cord.

\section{Changes in CSPG extracellular matrix composition in the cortex and spinal cord after $\mathrm{ChABC}$ treatment}

To determine changes in the extracellular matrix in the region of cortex containing YFP-labeled CSN cell bodies (Fig. 6A) we examined the pattern of CSPG degradation after ChABC treatment using an antibody against $\mathrm{C}-4-\mathrm{S}$, the stub epitope remaining after successful CS digestion with ChABC (Moon et al., 2001). In animals treated with penicillinase, no C-4-S immunoreactivity was apparent in the cortex (Fig. 6B). After IT ChABC treatment, more limited rostral dispersal of ChABC within CSF resulted in a border of C-4-S immunoreactivity superficially, at the pial surface of the cortex (Fig. 6C). However, after ICV delivery of ChABC, C-4-S was also apparent in deep cortical layers (layers $\mathrm{V}-\mathrm{VI}$ ) (Fig. 6D), including the region containing layer V YFPlabeled pyramidal neurons, indicating that only ICV treatment reaches the cell bodies of YFP-labeled neurons. Reactivity for WFA, a marker of CSPG-rich PNNs (Pizzorusso et al., 2002) was also examined. In animals treated with penicillinase, abundant WFA labeling was seen in the sensorimotor cortex (mean PNN count \pm SEM; $124.3 \pm 11.8$ ), in particular around neurons in cortical layers IV and VI but, as described previously (Brückner et al., 1998), not around layer V pyramidal neurons (Fig. 6E). This pattern of reactivity was not significantly altered after IT delivery of ChABC (mean $\mathrm{PNN}$ count $\pm \mathrm{SEM} ; 118.6 \pm 6.3, p=0.88$, one-way ANOVA, Tukey post hoc analysis) (Fig. $6 F$ ). However, after ICV delivery of ChABC, WFA reactivity was significantly reduced (mean PNN count \pm SEM; $77.0 \pm 6.0, p=0.01$, one-way ANOVA, Tukey post hoc analysis) and largely absent from neurons in the deeper cortical layers (Fig. 6G), indicating digestion of these CSPG-rich perineuronal nets in neighboring neurons after ICV, but not IT delivery. Thus, ICV ChABC treatment leads to changes in the extracellular matrix in the sensorimotor cortex but the neurons affected are principally neighboring neurons which contain PNNs, rather than the layer $\mathrm{V}$ projection neurons. Since ICV and IT ChABC treatment promote an equivalent degree of rescue from atrophy, yet produce such distinct patterns of CSPG digestion in the cortex, we considered the spinal cord as an alternative site of action.

Both descending and ascending axon projections were clearly labeled in sagittal sections of uninjured YFP-H mouse spinal cord (Fig. 7A). Four weeks after a dorsal column injury there was a clear disruption of both the descending corticospinal tract and the ascending projection in the dorsal columns, with classic retraction bulbs apparent at the severed axon endings and no evidence of regrowth into the injury site (Fig. 7B). The pattern of CSPG degradation in the spinal cord after ChABC treatment was assessed using the antibody against C-4-S. In lesioned animals treated with penicillinase, no C-4-S immunoreactivity was apparent (Fig. 7C). In contrast, after ChABC treatment C-4-S immunoreactivity was abundant in the lesioned spinal cord, with a similar pattern observed after IT or ICV delivery, with intense immunoreactivity typically apparent within and surrounding the lesion site, as well as in superficial white matter tracts rostral and caudal to the lesion epicenter (Fig. 7D,E, respectively). Thus, in vivo delivery of ChABC degrades CSPGs at the site of a spinal cord injury in the YFP-H mouse. As both ICV and IT ChABC treatment degrade CSPGs at the spinal injury site to a comparable degree, neuroprotective effects may be mediated here rather than at the cell body level in the cortex.

\section{$\mathrm{ChABC}$ treatment promotes growth of injured axons in the spinal cord of the YFP-H mouse}

We then examined whether ChABC treatment would induce sprouting of injured axons in the spinal cord of the YFP-H mouse, since the response of the cell body to axotomy may depend on the ability of injured axon tips to form growth cones and regenerative sprouts. In the spinal cord of lesioned animals treated with penicillinase there was no evidence of growth of YFP-labeled axons into the lesion site (mean fiber count per section \pm SEM; $1.3 \pm 0.3$ ) (Fig. $7 F, G)$, with the central lesion core virtually devoid of YFP-labeled fibers. In contrast, after IT treatment with $\mathrm{ChABC}$, significantly more fine fibers were observed growing into the lesion site, within the central core of necrotic 
tissue (mean fiber count per section \pm SEM; $5.2 \pm 0.9, p=0.01$, one-way ANOVA, Tukey post hoc analysis) (Fig. $7 H, I)$ which is known to be highly inhibitory and refractory to regrowth. Similar sprouting effects were observed after injury and ICV ChABC treatment (mean fiber count per section \pm SEM; $4.3 \pm 0.4$; $p=0.04$, one-way ANOVA, Tukey post hoc analysis). Thus, in vivo ChABC treatment after spinal cord injury in the YFP-H mouse leads to a robust sprouting response of injured axons at the lesion site, which could have a retrograde effect on cell body survival in the cortex.

\section{ChABC treatment is associated with increased MAPK, AKT, and PKC signaling at the spinal cord injury site} We investigated whether $\mathrm{ChABC}$ treatment could promote signaling changes in vivo by examining the expression and activation state of several distinct signaling pathways at the site of spinal cord injury 4 weeks after injury (a time point where neuroprotection and regenerative sprouting was observed) using Western blot analysis (Fig. 8). Extracellular signal regulated kinases 1 and 2 (ERK1/2, p44/42 MAPK) play an important role in cell survival, growth and differentiation in response to trophic factors and are activated upon threonine and tyrosine phosphorylation by a single upstream protein kinase, ERK kinase. ChABC treatment via both ICV and IT delivery promoted a significant increase in the phosphorylation of ERK1 (p44 MAPK) at the lesion site, compared with penicillinase-treated controls (Fig. $8 \mathrm{~A}, \mathrm{C}$ ) (normalized band intensity \pm SEM, penicillinase $0.80 \pm 0.10$; ICV ChABC $1.55 \pm 0.13, p=0.004$; IT ChABC $1.30 \pm 0.12, p=0.04$; one-way ANOVA with block design, Tukey post hoc analysis). The total expression of ERK1 in ChABC-treated animals was not significantly different to controls at 4 weeks after injury (Fig. 8 B) (penicillinase $4.42 \pm 1.17$; ICV ChABC $4.58 \pm 0.81$; IT ChABC $4.97 \pm 1.12, p>0.05)$ and no significant differences in the expression or phosphorylation state of ERK2 (p42 MAPK) were observed (Fig. 8A) (densitometry not shown).

Conventional isoforms of protein kinase $\mathrm{C}(\mathrm{PKC})$ include the serine/threonine kinases $\mathrm{PKC} \alpha, \mathrm{PKC} \beta \mathrm{I}, \mathrm{PKC} \beta \mathrm{II}$, and $\mathrm{PKC} \gamma$, which are regulated principally by intracellular calcium and diacylglycerol. Expression of the PKC $\beta \mathrm{II}$ isoform at the site of spinal injury was significantly increased after IT ChABC treatment compared with penicillinase-treated controls (Fig. 8D,E) (normalized band intensity \pm SEM, penicillinase $64.00 \pm 3.46$; IT ChABC 95.16 \pm 8.23, $\mathrm{P}=0.04$; one-way ANOVA with block design, Tukey post hoc analysis). PKC expression after ICV ChABC treatment was not significantly different from control (Fig. 8E) (ICV ChABC $63.63 \pm 16.69, p>0.05)$, and ChABC
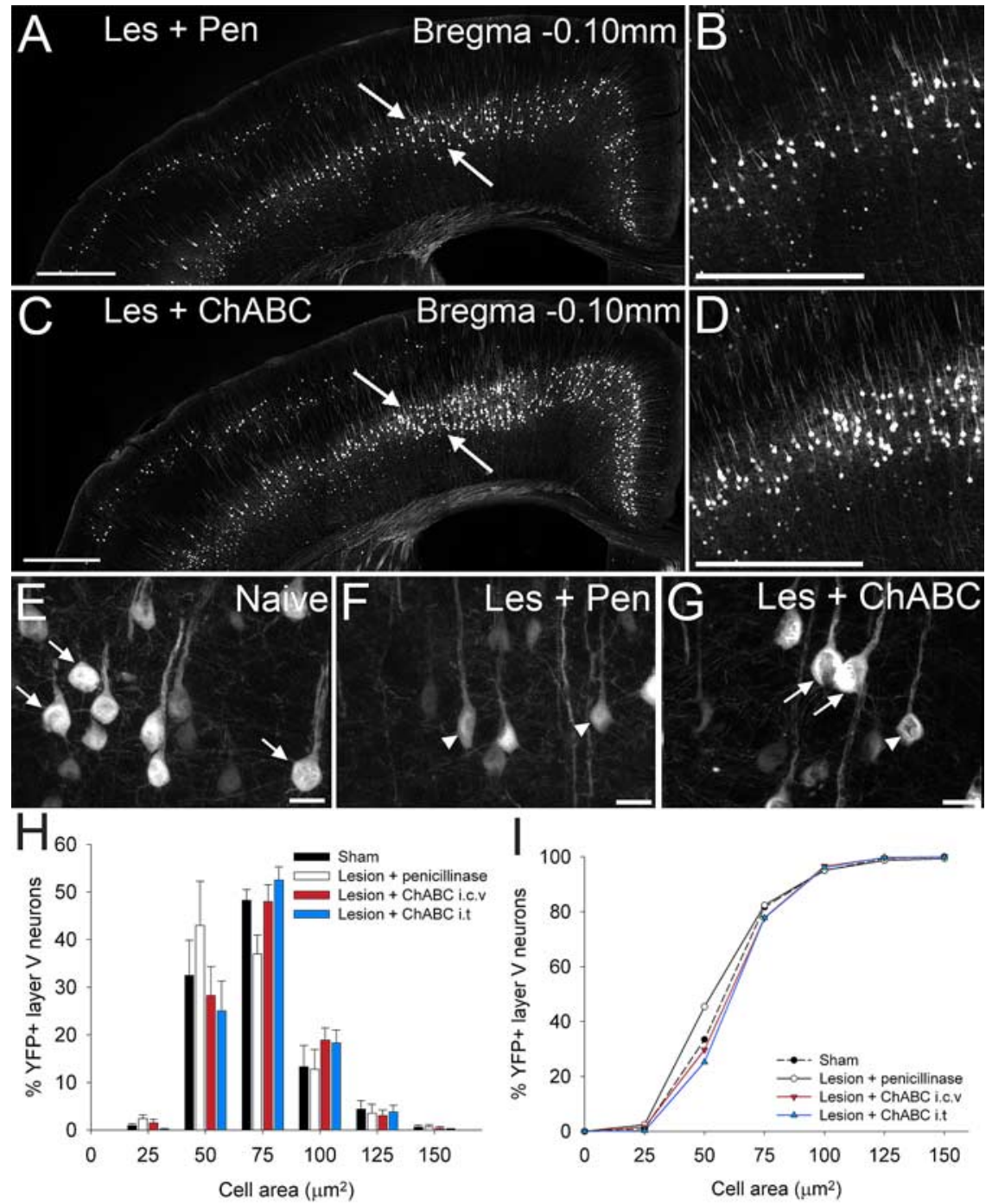

Figure 5. ChABC treatment, via two distinct methods of delivery, promotes neuroprotection of corticospinal projection neurons after spinal cord injury in the YFP-H mouse. In coronal sections through the YFP-H sensorimotor cortex at bregma $-0.10 \mathrm{~mm}$ $(\boldsymbol{A}-\boldsymbol{I})$, representative low $(\boldsymbol{A}, \boldsymbol{C})$ - and high $(\boldsymbol{B}, \boldsymbol{D})$-power images show many more large healthy YFP-labeled somata in the sensorimotor cortex after $C h A B C$ treatment $(\boldsymbol{C}, \boldsymbol{D})$ compared with penicillinase-treated animals $(\boldsymbol{A}, \boldsymbol{B})$. Higher-magnification cells in injured animals treated with penicillinase ( $\boldsymbol{F}$, arrowheads). After injury and $\mathrm{ChABC}$ treatment $(\boldsymbol{G})$, atrophy is apparent in a small number of neurons (arrowheads), with the majority retaining normal cell sizes (arrows). Histogram $(\boldsymbol{H})$ and cumuth sham-operated animals ( $p<0.05$, Kolmogorov-Smirnov test). ChABC treatment results in complete rescue of CSNs from Kolmogorov-Smirnov test). Cell size frequency distribution histograms display mean frequency $\pm S E M, n=4$ per treatment group. Scale bars: $500 \mu \mathrm{m}(\boldsymbol{A}, \boldsymbol{C}), 250 \mu \mathrm{m}(\boldsymbol{B}, \boldsymbol{D}), 20 \mu \mathrm{m}(\boldsymbol{E}, \boldsymbol{F}, \boldsymbol{G})$.

treatment had no significant effect on the total phosphorylation state of PKC isoforms at the site of spinal injury (Fig. $8 F$ ) (normalized band intensity \pm SEM, penicillinase $24.50 \pm 2.99$; ICV ChABC $24.01 \pm 5.84$; IT ChABC $33.70 \pm 10.61, p>0.05$; oneway ANOVA with block design, Tukey post hoc analysis).

The serine/threonine protein kinase AKT is a key mediator of survival signaling in neurons (Dudek et al., 1997; Yano et al., 1998), acting downstream of the lipid kinase, phosphatidylinositol-3 kinase. AKT expression at the lesion site was significantly increased in animals treated with $\mathrm{ChABC}$ via IT delivery compared with the penicillinase-treated group (Fig. $8 G, H$ ) (normalized band intensity \pm SEM, penicillinase, $2.70 \pm$ 0.90 ; IT ChABC $5.21 \pm 1.13, p=0.03$; one-way ANOVA with 


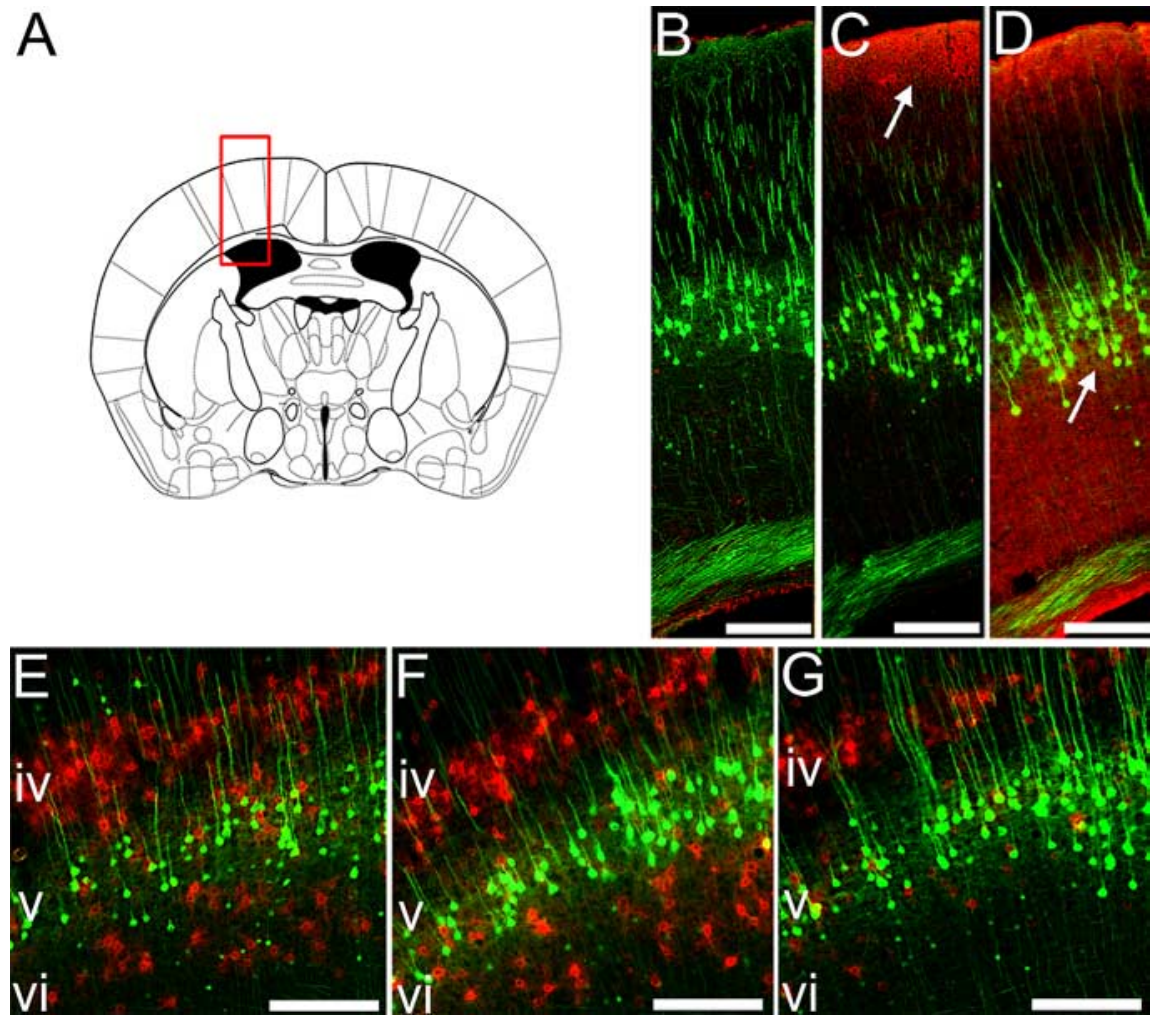

Figure 6. ICV but not IT delivery of ChABC degrades CSPGs close to layer V CSNs. Degradation of CSPGs in the sensorimotor cortex was evaluated at bregma $-0.46 \mathrm{~mm}(\boldsymbol{A})$. Immunoreactivity for chondroitin-4-sulfate $(\boldsymbol{C}-4-S)$ epitopes (red) reveals degradation of matrix CSPGs after cleavage of sugar side chains by $C h A B C(B-D)$. Representative photomicrographs show no $C-4-S$ immunoreactivity in the sensorimotor cortex of penicillinase-treated animals $(\boldsymbol{B})$. After IT delivery of ChABC to the spinal injury site, CSPG digestion is only observed close to the pial surface ( $\boldsymbol{C}$, arrow). ICV delivery of $C h A B C(\boldsymbol{D}$, arrow) results in more extensive CSPG digestion in the cortex, including the area containing layer V YFP-labeled pyramidal neurons (green). Wisteria floribunda agglutinin histochemistry $(\boldsymbol{E}-\boldsymbol{G})$ reveals (SPGs within perineuronal nets in the sensorimotor cortex (red). Prominent labeling is observed in cortical layers IV and VI in penicillinase-treated animals $(\boldsymbol{E})$. Labeling of PNNs is unchanged after IT delivery of ChABC $(\boldsymbol{F})$, but ICV ChABC delivery results in a marked reduction in PNNs in cortical layer VI, close to the cell bodies of YFP-labeled layer V CSNs (G). Scale bars, $200 \mu \mathrm{m}$.

block design, Tukey post hoc analysis). ChABC treatment via ICV delivery did not significantly alter AKT expression (Fig. $8 \mathrm{H}$ ) (ICV ChABC $3.17 \pm 0.71, p>0.05$; one-way ANOVA with block design, Tukey post hoc analysis) and serine-phosphorylation of the AKT regulatory domain was not significantly different between treatment groups (Fig. $8 I$ ) (penicillinase $0.21 \pm 0.05$; ICV ChABC $0.25 \pm 0.03$; IT ChABC $0.29 \pm 0.06, p>0.05$; one-way ANOVA with block design, Tukey post hoc analysis).

Phosphorylation and inhibition of glycogen synthase kinase $3 \beta$ (GSK $3 \beta$ ) is one mechanism by which activated AKT promotes neuronal survival (Cross et al., 1995; Hetman et al., 2000). We investigated whether increased expression of AKT after ChABC treatment was associated with downstream changes to GSK $3 \beta$. No significant differences in GSK3 $\beta$ expression were detected between penicillinase- and ChABC-treated animals (Fig. 8J, K) (normalized band intensity \pm SEM, penicillinase $41.44 \pm 3.02$; ICV ChABC $37.06 \pm 4.24$; IT ChABC $39.63 \pm 3.10, p>0.05$; one-way ANOVA with block design, Tukey post hoc analysis), and phosphorylation of GSK $3 \beta$ was not significantly different between treatment groups (Fig. $8 \mathrm{~L}$ ) (penicillinase $42.97 \pm 3.33$; ICV ChABC $38.59 \pm 3.00$; IT ChABC $48.26 \pm 5.16 ; p>0.05$; one-way ANOVA with block design, Tukey post hoc analysis).

Thus, ChABC treatment promoted a significant increase in the activation and expression of several intracellular kinases which play important roles in neuronal survival and outgrowth.
ChABC treatment therefore significantly modifies the signaling environment of the injured spinal cord, which may contribute to protective retrograde effects on lesioned CSNs.

\section{Discussion}

Using the YFP-H transgenic mouse as a novel method to study degenerative changes and repair, we demonstrate that corticospinal neurons undergo progressive atrophy after thoracic spinal cord injury and that degradation of CSPGs by ChABC restores soma size to that of uninjured controls. We also demonstrate that ChABC administered to the spinal cord injury site has neuroprotective effects equivalent to intracerebroventricular ChABC treatment, which also degrades CSPGs around the cell bodies. We further demonstrate that $\mathrm{Ch} \mathrm{ABC}$ treatment regulates several signaling cascades at the site of injury and renders the lesion epicenter more permissive to the in-growth of lesioned fibers. Together this work demonstrates that modification of the extracellular matrix at the spinal cord injury site promotes a protective response in injured projection neurons and represents a novel mechanism underlying ChABC-mediated repair.

\section{The YFP-H mouse as a novel tool for} spinal cord injury studies

Degeneration of spinal projection neurons has classically been studied using retrograde tracing methodology and has proved a valuable tool for assessing changes after injury and neuroprotective treatment strategies (Giehl and Tetzlaff, 1996; Kobayashi et al., 1997; Bradbury et al., 1998). After spinal cord injury in adult rats a number of such studies have provided evidence for both atrophy (McBride et al., 1989; Tang et al., 2004) and apoptotic cell death in injured CSNs (Hains et al., 2003; Sasaki et al., 2006). Other studies have indicated developmental differences in the response of CSNs to axotomy, with cell death observed when CSNs are injured before $14 \mathrm{~d}$, but not at later time points after CST innervation of spinal cord targets, when atrophy but not cell death was apparent (Merline and Kalil, 1990). In the present study, using a novel transgenic mouse model, we observed significant atrophy of CSN somata after thoracic spinal cord injury with no evidence for cell loss or apoptosis.

Methodologically, however, injection of tracer dye is prone to variability as well as being invasive. We found that intrinsic labeling of layer $\mathrm{V}$ projection neurons in the YFP-H mouse provides a reliable marker for determining CSN cell atrophy after spinal injury, highly comparable with traditional retrograde tracing methods and therefore, the YFP-H mouse line offers a distinct advantage. Furthermore, as layer V pyramidal neurons throughout the forebrain are labeled in the YFP-H mouse, this enables the study of both injured and intact neighboring pyramidal neurons, not only those back-traced from the lesion. Thus, we were able to study the effects of $\mathrm{ChABC}$ on neighboring cortical neurons that would have been treated by ICV infusion of ChABC but which do 


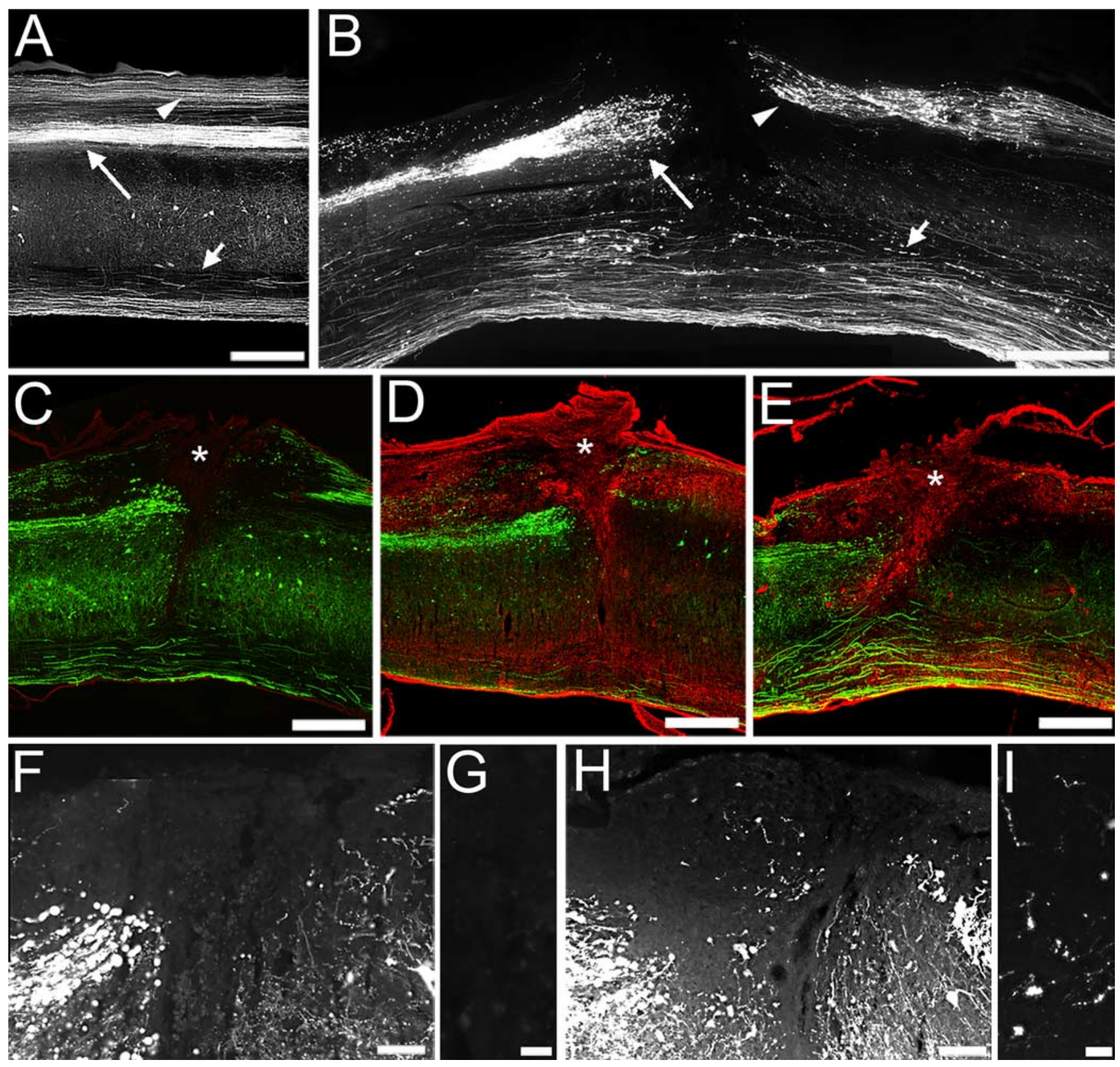

Figure 7. ChABC treatment degrades CSPGs at the site of spinal cord injury and promotes regeneration of YFP-labeled fibers. Sagittal section of the naive $(\boldsymbol{A})$ and injured ( $\boldsymbol{B}-\boldsymbol{I})$ YFP-H mouse spinal cord shows that crush injury to the dorsal columns ( $\boldsymbol{B}$ ) disrupts the main descending (ST projection (long arrows) and the ascending dorsal column projection (arrowheads), leaving the ventral tracts intact (short arrows). At the injury epicenter (asterisks), C-4-S immunolabeling of degraded matrix CSPGs (red) is absent in penicillinase-treated animals (C), but both intrathecal (D) and intracerebroventricular $(\boldsymbol{E})$ delivery of ChABC results in extensive digestion of CSPGs within the lesion site, the surrounding scar and extending rostrocaudally in white matter tracts (arrowheads). Low $(\boldsymbol{F}, \boldsymbol{H})$ - and high $(\boldsymbol{G}, \boldsymbol{I})$-power images show that the lesion epicenter is devoid of YFP-labeled fibers in penicillinase-treated animals $(\boldsymbol{F}, \boldsymbol{G})$. In contrast, after IT ChABC treatment, numerous small YFP-labeled fibers are apparent $(\boldsymbol{H}, \boldsymbol{I})$ indicating regenerative growth of lesioned YFP-labeled axons into the modified scar. Scale bars: $500 \mu \mathrm{m}(\boldsymbol{A}-\boldsymbol{E}), 100 \mu \mathrm{m}(\boldsymbol{F}, \boldsymbol{H}), 20 \mu \mathrm{m}(\boldsymbol{G}, \boldsymbol{I})$.

not project to the thoracic spinal cord. We found no evidence of cell atrophy or hypertrophy in uninjured neighboring projection neurons after ChABC treatment, indicating a specific "rescue" effect on injured neurons. Furthermore, YFP-H mouse studies are not restricted to examining effects in only the cell body since the fluorescent protein labels the neuron in its entirety (Feng et al., 2000), allowing the study of both cell bodies in the cortex and projecting axons in the spinal cord. Thus, we were able to observe growth of YFP-labeled fibers within the lesion site after ChABC treatment. As axonal labeling in the spinal cord of the YFP-H mouse is not purely CST, these sprouting fibers are likely to be a mixture of ascending dorsal column as well as CST axons. However, it should be noted that since fibers are prelabeled, how ChABC treatment might modify the degeneration and clearance of injured axons cannot be determined. Nevertheless, we have previously shown that ChABC treatment promotes regeneration (Bradbury et al., 2002) and sprouting (Barritt et al., 2006) of the injured CST, using conventional tracing techniques. Thus, the apparent growth of intrinsically labeled injured fibers into the lesion epicenter observed here after ChABC treatment supports the hypothesis that the outgrowth and formation of novel contacts by injured axons may provide access to protective cues in the injured spinal cord which promote the rescue of lesioned projection neurons, possibly via a retrograde mechanism. 

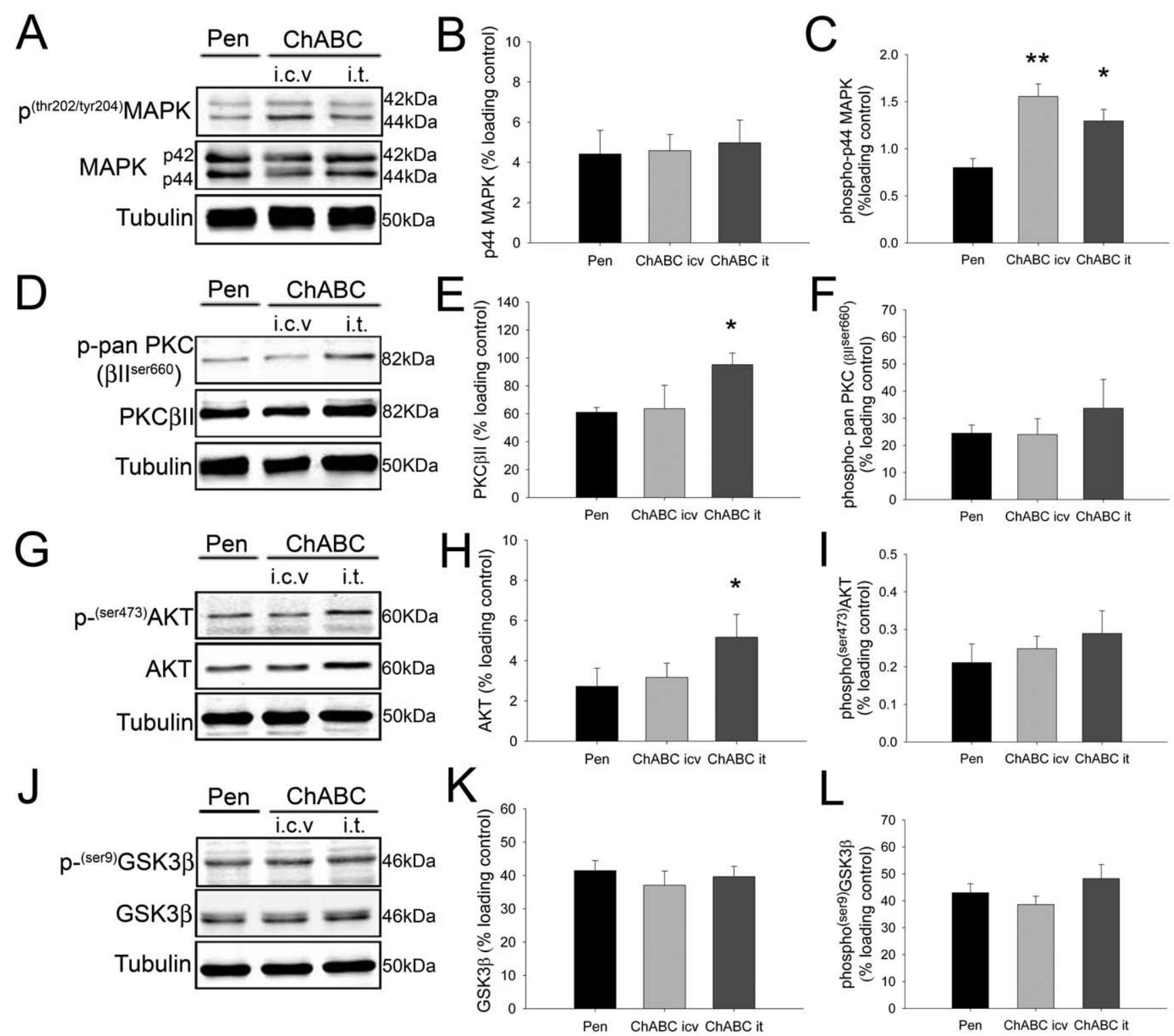

Figure 8. ChABC treatment upregulates multiple signaling pathways at the site of spinal cord injury. Four weeks after dorsal column injury, the expression and activation state of intracellular signaling pathways was evaluated at the site of injury. Representative Western blots and densitometric quantification are shown for p44/42 MAPK (A-C), PKC (D-F), AKT (G-I), and GSK3 $\beta(J-L)$. Treatment with ChABC using either ICV or IT delivery promoted a significant increase in the phosphorylation of p44 MAPK (ERK1) after spinal cord injury compared with penicillinase-treated controls (C) but did not alter the total expression level of the kinase $(\boldsymbol{B})$. IT delivery of $\mathrm{ChABC}$, but not treatment via ICV delivery, promoted a significant increase in the expression level of the PKC $\beta$ Il isoform $(\boldsymbol{E})$ and the serine/threonine kinase AKT $(\boldsymbol{H})$ compared with the penicillinase-treated group. The phosphorylation state of PKC $(\boldsymbol{F})$ and AKT $(\boldsymbol{I})$ was not significantly changed from control, and neither the expression $(\boldsymbol{K})$ or phosphorylation $(\boldsymbol{L})$ of GSK3 $\beta$ in the spinal cord was significantly altered by ChABC treatment. Densitometric values for target proteins or phosphoproteins were normalized against a $\beta$-III-tubulin loading control for each sample. Bar graphs represent mean normalized densitometric reading \pm SEM of 4 animals per group. ${ }^{*} p<0.05,{ }^{* *} p<0.01$, one-way ANOVA with block design using Tukey post hoc analysis.

Is neuroprotection a result of increased sprouting and growth cone formation at the injury site?

In this study the digestion of cortical CSPGs after ICV ChABC treatment was limited and restricted largely to cortical layers neighboring layer $\mathrm{V}$ pyramidal neurons, rather than affecting layer $\mathrm{V}$ itself. It remains possible therefore, that $\mathrm{ChABC}$ promotes the rescue of injured CSNs, not by directly affecting the cell body, but by modifying the extracellular environment in the dendritic field of these neurons, providing supportive cues to the apical or basal dendrites. The current findings might also suggest however, that neuroprotection of injured projection neurons may be linked to processes of growth at the injury site. For example, growth cone motility may lead to a more robust response at the level of the cell body after injury. Evidence that exposure to CSPGs stimulates the formation of dystrophic growth cones on lesioned sensory axons (Tom et al., 2004) suggests that in the present study reducing CSPG inhibition at the injury site enabled growth cone formation and neurite sprouting, which retrogradely promoted rescue of the cell body from atrophy.

Other factors are known to be important contributors to the lack of growth and repair after spinal cord injury, such as inhibitory factors associated with CNS myelin (Liu et al., 2006; Chaudhry and Filbin, 2007; Gonzenbach and Schwab, 2008) and both anti-Nogo and CSPG degradation strategies have been shown to have potent effects on restoring function to spinalinjured adult rats and on promoting axonal regeneration and 
sprouting. However, recent studies in adult monkeys have demonstrated that while anti-Nogo therapy promotes sprouting of CST axons at the lesion site after spinal injury (Freund et al., 2006), it does not prevent the shrinkage of CSN somata (Beaud et al., 2008). Thus, regenerative sprouting of injured axons per se may not be a sufficient stimulus to mount a neuroprotective response in the cell body of injured projection neurons. This suggests that there is something specific about the changes in the cellular environment at the spinal cord injury site after CSPG degradation that favors growth and has a retrograde neuroprotective effect. We have identified some of the signaling changes that may be important in this process.

\section{Intracellular signaling changes after spinal cord injury and in vivo ChABC treatment}

We found that ChABC treatment after spinal cord injury modified the expression and activation state of several important intracellular kinase cascades in vivo. Signaling changes were apparent 2 weeks after completion of the ChABC dosing period, indicating that this promotes long-lasting molecular changes to cells at the lesion site. Thus, four weeks after injury the activation of ERK1, indicated by phosphorylation, was significantly elevated in ChABC-treated spinal cord compared with penicillinasetreated controls. Furthermore, the expression level, but not the phosphorylation state, of PKC and AKT was elevated at the injury site after IT ChABC treatment, which may reflect an upregulation of these pathways in response to modification of the extracellular environment. It is not certain from these data, how such changes might affect the response of lesioned projection neurons after spinal cord injury, but these intracellular kinase cascades are known to be involved in processes of growth and survival. For example, ERK1/MAPK cascades are activated by a diverse range of extracellular stimuli and play an important role in cell survival, growth, and differentiation in response to trophic factors. In particular, MAPK cascades have an established role in mediating neuronal survival via transcription-dependent mechanisms involving CREB and via the phosphorylation of proapoptotic targets (Xing et al., 1996; Bonni et al., 1999). Other evidence suggests a role for ERK signaling in axonal growth (Zhou and Snider, 2006), including activity in the regulation of growth-associated cytoskeletal proteins such as MAP1b (Goold and Gordon-Weeks, 2005) and the regulation of local protein synthesis in neuronal growth cones (Campbell and Holt, 2003). AKT is also known to be a critical mediator of survival signaling in neurons (Dudek et al., 1997; Yano et al., 1998) but the role of PKC is less clear. While PKC isoforms are known to play an important role in cytoskeletal reorganization, plasticity, and axonal outgrowth via phosphorylation of regeneration-associated genes such as growthassociated protein-43 (Aigner et al., 1995; He et al., 1997), PKC pathways have also been implicated in the growth inhibitory activity of myelin and CSPGs, and inhibiting PKC activity can promote regeneration of sensory (but not CST) axons after spinal cord injury (Sivasankaran et al., 2004; Koprivica et al., 2005). The signaling changes at the lesion site reported here after ChABC treatment coincide with favorable anatomical changes, namely the restoration of cell size in injured projection neurons and evidence of growth within the lesion. Thus, at 4 weeks after injury activation of ERK1 and upregulation of PKC and AKT may contribute to ChABC-mediated repair. This is the first demonstration of molecular changes occurring in vivo after ChABC treatment and provides key evidence that CSPG degradation modulates the intracellular signaling environment at the spinal cord injury site

\section{Mechanisms underlying neuroprotective effects after ChABC treatment}

It has been suggested that degradation of CSPGs may generate repair products, such as CSPG-disaccharides which are neuroprotective to retinal ganglion cells after glutamatergic insult (Rolls et al., 2004). Although the in vivo existence of CSPGdisaccharides remains to be demonstrated, it is likely that enzymatic modification of CSPGs could lead to the release of other bound factors beneficial to repair, since highly sulfated forms of chondroitin sulfate can bind a variety of growth factors and other proteins (Crespo et al., 2007). The MAPK and AKT signaling cascades shown to be altered here are known to be involved in downstream signaling in response to neurotrophic factors (Bonni et al., 1999; Goold and Gordon-Weeks, 2005), suggesting that the neuroprotective effects observed may be due to increased access to neurotrophic factors after ChABC treatment. Indeed, the neuroprotective effects are comparable to classic studies where neuroprotection of axotomized corticospinal and rubrospinal projection neurons has been observed after exogenous delivery of neurotrophic factors (Tetzlaff et al., 1994; Giehl and Tetzlaff, 1996; Kobayashi et al., 1997). While these studies administered neurotrophic factors to axotomized cell bodies, we demonstrate long distance retrograde survival effects with treatment restricted to the injury site, similar to the effects observed after transplantation of neurotrophic factor secreting fibroblasts into the injured spinal cord (Tobias et al., 2003) or olfactory ensheathing cells, whose neuroprotective effects were attributed to elevated levels of BDNF at the spinal injury site (Sasaki et al., 2006).

Thus, using a novel transgenic approach we demonstrate that CSPG degradation promotes neuroprotection of axotomized projection neurons as well as sprouting of injured axons, demonstrating multiple reparative effects of ChABC treatment. Furthermore, we provide key evidence that CSPG degradation modulates the intracellular signaling environment at the spinal cord injury site, which might contribute to these protective effects.

\section{References}

Aigner L, Arber S, Kapfhammer JP, Laux T, Schneider C, Botteri F, Brenner HR, Caroni P (1995) Overexpression of the neural growth-associated protein GAP-43 induces nerve sprouting in the adult nervous system of transgenic mice. Cell 83:269-278.

Asher RA, Morgenstern DA, Fidler PS, Adcock KH, Oohira A, Braistead JE, Levine JM, Margolis RU, Rogers JH, Fawcett JW (2000) Neurocan is upregulated in injured brain and in cytokine-treated astrocytes. J Neurosci 20:2427-2438.

Asher RA, Morgenstern DA, Shearer MC, Adcock KH, Pesheva P, Fawcett JW (2002) Versican is upregulated in CNS injury and is a product of oligodendrocyte lineage cells. J Neurosci 22:2225-2236.

Barritt AW, Davies M, Marchand F, Hartley R, Grist J, Yip P, McMahon SB, Bradbury EJ (2006) Chondroitinase ABC promotes sprouting of intact and injured spinal systems after spinal cord injury. J Neurosci 26:10856-10867.

Beaud ML, Schmidlin E, Wannier T, Freund P, Bloch J, Mir A, Schwab ME, Rouiller EM (2008) Anti-Nogo-A antibody treatment does not prevent cell body shrinkage in the motor cortex in adult monkeys subjected to unilateral cervical cord lesion. BMC Neurosci 9:5.

Bonni A, Brunet A, West AE, Datta SR, Takasu MA, Greenberg ME (1999) Cell survival promoted by the Ras-MAPK signaling pathway by transcription-dependent and -independent mechanisms. Science 286:1358-1362.

Bradbury EJ, McMahon SB (2006) Spinal cord repair strategies: why do they work? Nat Rev Neurosci 7:644-653.

Bradbury EJ, King VR, Simmons LJ, Priestley JV, McMahon SB (1998) NT-3, but not BDNF, prevents atrophy and death of axotomized spinal cord projection neurons. Eur J Neurosci 10:3058-3068.

Bradbury EJ, Khemani S, Von R, King, Priestley JV, McMahon SB (1999) 
NT-3 promotes growth of lesioned adult rat sensory axons ascending in the dorsal columns of the spinal cord. Eur J Neurosci 11:3873-3883.

Bradbury EJ, Moon LD, Popat RJ, King VR, Bennett GS, Patel PN, Fawcett JW, McMahon SB (2002) Chondroitinase ABC promotes functional recovery after spinal cord injury. Nature 416:636-640.

Brückner G, Bringmann A, Härtig W, Köppe G, Delpech B, Brauer K (1998) Acute and long-lasting changes in extracellular-matrix chondroitinsulphate proteoglycans induced by injection of chondroitinase $\mathrm{ABC}$ in the adult rat brain. Exp Brain Res 121:300-310.

Busch SA, Silver J (2007) The role of extracellular matrix in CNS regeneration. Curr Opin Neurobiol 17:120-127.

Cafferty WBJ, Yang SH, Duffy PJ, Li S, Strittmatter SM (2007) Functional axonal regeneration through astrocytic scar genetically modified to digest chondroitin sulfate proteoglycans. J Neurosci 27:2176-2185.

Cafferty WBJ, Bradbury EJ, Lidierth M, Jones M, Duffy PJ, Pezet S, McMahon SB (2008) Chondroitinase ABC-mediated plasticity of spinal sensory function. J Neurosci 28:11998-12009.

Caggiano AO, Zimber MP, Ganguly A, Blight AR, Gruskin EA (2005) Chondroitinase $\mathrm{ABCI}$ improves locomotion and bladder function following contusion injury of the rat spinal cord. J Neurotrauma 22:226-239.

Campbell DS, Holt CE (2003) Apoptotic pathway and MAPKs differentially regulate chemotropic responses of retinal growth cones. Neuron 37:939-952.

Chau CH, Shum DK, Li H, Pei J, Lui YY, Wirthlin L, Chan YS, Xu XM (2004) Chondroitinase $\mathrm{ABC}$ enhances axonal regrowth through Schwann cellseeded guidance channels after spinal cord injury. FASEB J 18:194-196.

Chaudhry N, Filbin MT (2007) Myelin-associated inhibitory signaling and strategies to overcome inhibition. J Cereb Blood Flow Metab 27:1096-1107.

Crespo D, Asher RA, Lin R, Rhodes KE, Fawcett JW (2007) How does chondroitinase promote functional recovery in the damaged CNS? Exp Neurol 206:159-171.

Cross DA, Alessi DR, Cohen P, Andjelkovich M, Hemmings BA (1995) Inhibition of glycogen synthase kinase- 3 by insulin mediated by protein kinase B. Nature 378:785-789.

Davies SJ, Goucher DR, Doller C, Silver J (1999) Robust regeneration of adult sensory axons in degenerating white matter of the adult rat spinal cord. J Neurosci 19:5810-5822.

Dou CL, Levine JM (1994) Inhibition of neurite growth by the NG2 chondroitin sulfate proteoglycan. J Neurosci 14:7616-7628.

Dudek H, Datta SR, Franke TF, Birnbaum MJ, Yao R, Cooper GM, Segal RA, Kaplan DR, Greenberg ME (1997) Regulation of neuronal survival by the serine-threonine protein kinase Akt. Science 275:661-665.

English AW, Meador W, Carrasco DI (2005) Neurotrophin-4/5 is required for the early growth of regenerating axons in peripheral nerves. Eur J Neurosci 21:2624-2634.

Faissner A, Steindler D (1995) Boundaries and inhibitory molecules in developing neural tissues. Glia 13:233-254.

Feng G, Mellor RH, Bernstein M, Keller-Peck C, Nguyen QT, Wallace M, Nerbonne JM, Lichtman JW, Sanes JR (2000) Imaging neuronal subsets in transgenic mice expressing multiple spectral variants of GFP. Neuron 28:41-51.

Fouad K, Schnell L, Bunge MB, Schwab ME, Liebscher T, Pearse DD (2005) Combining Schwann cell bridges and olfactory-ensheathing glia grafts with chondroitinase promotes locomotor recovery after complete transection of the spinal cord. J Neurosci 25:1169-1178.

Freund P, Schmidlin E, Wannier T, Bloch J, Mir A, Schwab ME, Rouiller EM (2006) Nogo-A-specific antibody treatment enhances sprouting and functional recovery after cervical lesion in adult primates. Nat Med 12:790-792.

Galtrey CM, Fawcett JW (2007) The role of chondroitin sulfate proteoglycans in regeneration and plasticity in the central nervous system. Brain Res Rev 54:1-18.

García-Alías G, Lin R, Akrimi SF, Story D, Bradbury EJ, Fawcett JW (2008) Therapeutic time window for the application of chondroitinase ABC after spinal cord injury. Exp Neurol 210:331-338.

Giehl KM, Tetzlaff W (1996) BDNF and NT-3, but not NGF, prevent axotomy-induced death of rat corticospinal neurons in vivo. Eur J Neurosci 8:1167-1175.

Gonzenbach RR, Schwab ME (2008) Disinhibition of neurite growth to repair the injured adult CNS: focusing on Nogo. Cell Mol Life Sci 65:161-176.
Goold RG, Gordon-Weeks PR (2005) The MAP kinase pathway is upstream of the activation of GSK3beta that enables it to phosphorylate MAP1B and contributes to the stimulation of axon growth. Mol Cell Neurosci 28:524-534.

Grimpe B, Pressman Y, Lupa MD, Horn KP, Bunge MB, Silver J (2005) The role of proteoglycans in Schwann cell/astrocyte interactions and in regeneration failure at PNS/CNS interfaces. Mol Cell Neurosci 28:18-29.

Hains BC, Black JA, Waxman SG (2003) Primary cortical motor neurons undergo apoptosis after axotomizing spinal cord injury. J Comp Neurol 462:328-341.

He Q, Dent EW, Meiri KF (1997) Modulation of actin filament behavior by GAP-43 (neuromodulin) is dependent on the phosphorylation status of serine 41, the protein kinase C site. J Neurosci 17:3515-3524.

Hetman M, Cavanaugh JE, Kimelman D, Xia Z (2000) Role of glycogen synthase kinase- $3 \beta$ in neuronal apoptosis induced by trophic withdrawal. J Neurosci 20:2567-2574.

Houle JD, Tom VJ, Mayes D, Wagoner G, Phillips N, Silver J (2006) Combining an autologous peripheral nervous system "bridge" and matrix modification by chondroitinase allows robust, functional regeneration beyond a hemisection lesion of the adult rat spinal cord. J Neurosci 26:7405-7415.

Jones LL, Margolis RU, Tuszynski MH (2003) The chondroitin sulfate proteoglycans neurocan, brevican, phosphacan, and versican are differentially regulated following spinal cord injury. Exp Neurol 182:399-411.

Kobayashi NR, Fan DP, Giehl KM, Bedard AM, Wiegand SJ, Tetzlaff W (1997) BDNF and NT-4/5 prevent atrophy of rat rubrospinal neurons after cervical axotomy, stimulate GAP-43 and T $\alpha 1$-tubulin mRNA expression, and promote axonal regeneration. J Neurosci 17:9583-9595.

Koprivica V, Cho KS, Park JB, Yiu G, Atwal J, Gore B, Kim JA, Lin E, TessierLavigne M, Chen DF, He Z (2005) EGFR activation mediates inhibition of axon regeneration by myelin and chondroitin sulfate proteoglycans. Science 310:106-110.

Liu BP, Cafferty WBJ, Budel SO, Strittmatter SM (2006) Extracellular regulators of axonal growth in the adult central nervous system. Philos Trans R Soc Lond B Biol Sci 361:1593-1610.

Massey JM, Hubscher CH, Wagoner MR, Decker JA, Amps J, Silver J, Onifer SM (2006) Chondroitinase ABC digestion of the perineuronal net promotes functional collateral sprouting in the cuneate nucleus after cervical spinal cord injury. J Neurosci 26:4406-4414.

Massey JM, Amps J, Viapiano MS, Matthews RT, Wagoner MR, Whitaker CM, Alilain W, Yonkof AL, Khalyfa A, Cooper NG, Silver J, Onifer SM (2008) Increased chondroitin sulfate proteoglycan expression in denervated brainstem targets following spinal cord injury creates a barrier to axonal regeneration overcome by chondroitinase $\mathrm{ABC}$ and neurotrophin-3. Exp Neurol 209:426-445.

McBride RL, Feringa ER, Garver MK, Williams JK Jr (1989) Prelabeled red nucleus and sensorimotor cortex neurons of the rat survive 10 and 20 weeks after spinal cord transection. J Neuropathol Exp Neurol 48:568-576.

McKeon RJ, Höke A, Silver J (1995) Injury-induced proteoglycans inhibit the potential for laminin-mediated axon growth on astrocytic scars. Exp Neurol 136:32-43.

Merline M, Kalil K (1990) Cell death of corticospinal neurons is induced by axotomy before but not after innervation of spinal targets. J Comp Neurol 296:506-516.

Moon LD, Asher RA, Rhodes KE, Fawcett JW (2001) Regeneration of CNS axons back to their target following treatment of adult rat brain with chondroitinase ABC. Nat Neurosci 4:465-466.

Paxinos G, Franklin KBJ (2001) The mouse brain in stereotaxic coordinates. San Diego: Academic.

Pizzorusso T, Medini P, Berardi N, Chierzi S, Fawcett JW, Maffei L (2002) Reactivation of ocular dominance plasticity in the adult visual cortex. Science 298:1248-1251.

Rolls A, Avidan H, Cahalon L, Schori H, Bakalash S, Litvak V, Lev S, Lider O, Schwartz M (2004) A disaccharide derived from chondroitin sulphate proteoglycan promotes central nervous system repair in rats and mice. Eur J Neurosci 20:1973-1983.

Sasaki M, Hains BC, Lankford KL, Waxman SG, Kocsis JD (2006) Protection of corticospinal tract neurons after dorsal spinal cord transection and engraftment of olfactory ensheathing cells. Glia 53:352-359.

Sivasankaran R, Pei J, Wang KC, Zhang YP, Shields CB, Xu XM, He Z (2004) 
PKC mediates inhibitory effects of myelin and chondroitin sulfate proteoglycans on axonal regeneration. Nat Neurosci 7:261-268.

Smith-Thomas LC, Fok-Seang J, Stevens J, Du JS, Muir E, Faissner A, Geller HM, Rogers JH, Fawcett JW (1994) An inhibitor of neurite outgrowth produced by astrocytes. J Cell Sci 107:1687-1695.

Snow DM, Lemmon V, Carrino DA, Caplan AI, Silver J (1990) Sulfated proteoglycans in astroglial barriers inhibit neurite outgrowth in vitro. Exp Neurol 109:111-130.

Tang X, Davies JE, Davies SJ (2003) Changes in distribution, cell associations, and protein expression levels of NG2, neurocan, phosphacan, brevican, versican $\mathrm{V} 2$, and tenascin-C during acute to chronic maturation of spinal cord scar tissue. J Neurosci Res 71:427-444.

Tang XQ, Wang Y, Huang ZH, Han JS, Wan Y (2004) Adenovirus-mediated delivery of GDNF ameliorates corticospinal neuronal atrophy and motor function deficits in rats with spinal cord injury. Neuroreport 15:425-429.

Tester NJ, Howland DR (2008) Chondroitinase ABC improves basic and skilled locomotion in spinal cord injured cats. Exp Neurol 209:483-496.

Tetzlaff W, Kobayashi NR, Giehl KM, Tsui BJ, Cassar SL, Bedard AM (1994) Response of rubrospinal and corticospinal neurons to injury and neurotrophins. Prog Brain Res 103:271-286.

Tobias CA, Shumsky JS, Shibata M, Tuszynski MH, Fischer I, Tessler A, Murray M (2003) Delayed grafting of BDNF and NT-3 producing fibro- blasts into the injured spinal cord stimulates sprouting, partially rescues axotomized red nucleus neurons from loss and atrophy, and provides limited regeneration. Exp Neurol 184:97-113.

Tom VJ, Steinmetz MP, Miller JH, Doller CM, Silver J (2004) Studies on the development and behavior of the dystrophic growth cone, the hallmark of regeneration failure, in an in vitro model of the glial scar and after spinal cord injury. J Neurosci 24:6531-6539.

Xing J, Ginty DD, Greenberg ME (1996) Coupling of the RAS-MAPK pathway to gene activation by RSK2, a growth factor-regulated CREB kinase. Science 273:959-963.

Yano S, Tokumitsu H, Soderling TR (1998) Calcium promotes cell survival through CaM-K kinase activation of the protein-kinase-B pathway. Nature 396:584-587.

Yick LW, So KF, Cheung PT, Wu WT (2004) Lithium chloride reinforces the regeneration-promoting effect of chondroitinase $\mathrm{ABC}$ on rubrospinal neurons after spinal cord injury. J Neurotrauma 21:932-943.

Zhou FQ, Snider WD (2006) Intracellular control of developmental and regenerative axon growth. Philos Trans R Soc Lond B Biol Sci 361:1575-1592.

Zuo J, Neubauer D, Dyess K, Ferguson TA, Muir D (1998) Degradation of chondroitin sulfate proteoglycan enhances the neurite-promoting potential of spinal cord tissue. Exp Neurol 154:654-662. 